\title{
1 Out-of-plane response of masonry walls strengthened using 2 textile-mortar system
}

3 F. A. Kariou ${ }^{1}$, S. P. Triantafyllou ${ }^{2}$, D. A. Bournas ${ }^{3}$ and L. N. Koutas ${ }^{4}$

1,2 Centre for Structural Engineering and Informatics, Faculty of Engineering, The University of Nottingham, NG7 2RD, Nottingham, UK

6 1 florentia.kariou@ nottingham.ac.uk, ${ }^{2}$ savvas.triantafyllou@ @ottingham.ac.uk

$7 \quad{ }^{3}$ European Commission, Joint Research Centre (JRC), Directorate for Space, Security

8 and Migration, Safety and Security of Buildings Unit, via E. Fermi 2749, I-21027 Ispra,

9 Italy, dionysios.bournas@ec.europa.eu

$10{ }^{4}$ Elected Assistant Professor, Dept. of Civil Engrg., Univ. of Thessaly, Volos GR-38221,

11 Greece. Formerly: Post-Doctoral Research Associate, Dept. of Civil and Structural

12 Engrg, Univ. of Sheffield, UK. Email: koutasciv@ gmail.com

\section{Abstract}

The out-of-plane response of masonry walls strengthened with textile-reinforced mortar (TRM) is experimentally investigated in this work. Medium-scale three-point bending tests were carried out on 18 specimens comprising a set of 9 single-wythe and 9 double-wythe brick masonry walls. Key investigated parameters involved the textile reinforcement ratio, the textile material, the coating of the textile reinforcement with epoxy resin, and the wall thickness. Experimental results suggest that TRM significantly increase the load bearing capacity of masonry walls. The amount of reinforcement utilised affects both the strength and deformation characteristics of the corresponding specimens, while it may alter the failure mode. Resin coating on the textile is found to be beneficial for the performance of the TRM overlays.

Keywords: Textile Reinforced Mortars, masonry, coated textiles

\section{Introduction}

Unreinforced masonry is among the oldest construction systems worldwide. Masonry structures currently comprise a significant percentage of the existing building stock. Recent catastrophic events such as the earthquakes in L'Aquila (2009), Tohoku, Japan (2011), Christchurch (2011), Northern Italy (2012), and Central Italy (2016-2017) have tragically pointed out the need for restoration and strengthening of existing masonry structures. Structural strengthening interventions have been repeatedly documented as an effective method to not only preserve masonry structures but also to protect human lives, [see, e.g., 1, 2]. Masonry structures are also prone to ageing related structural deterioration, accelerated by the effect of adverse environmental actions, e.g., high speed winds and heavy rainfalls. Typical examples of partial collapse due to ageing include the Magdeen Tower [3] and the Feltham bridge [4] events. With the objective of mitigating such issues and also increase the durability and resilience of existing structures structural rehabilitation and strengthening techniques are employed. Structural strengthening further enables existing structure to operate under increased operational loads driven by current societal needs. Requirements for sustaining accidental events such as blast and impact, further necessitate upgrading of existing structures [5]. 
1 Due to the generic brittle response of unreinforced masonry (URM), improved structural 2 resilience can be achieved by increasing both the strength and the ductility of the structure, 3 thus introducing additional defence mechanisms [6-8]. To this point, several retrofitting 4 strategies have been introduced and implemented to improve the resilience of masonry structures, e.g., grouting, post-tensioning, concrete jacketing and Fibre Reinforced Polymer (FRP) composites amongst many [9]. Several researchers have examined the performance of FRP strengthened masonry structures [see, e.g., 10-17].

8 Despite their well-documented advantages (i.e. high strength and stiffness to weight ratio, corrosion resistance, ease and speed of application), the FRP strengthening technique entails several drawbacks, i.e., poor behaviour at moderate to high temperatures, combustibility, high costs, and safety-hazards for the manual workers. These are related to the properties of the organic resins used to impregnate the fibres as for example these have been reported to deteriorate for temperatures below or close to their glass transition temperature (usually in the range of $50-120^{\circ} \mathrm{C}$ ), see, e.g., [55, 56]. Epoxy-resins furthermore decompose thermally, releasing heat, smoke, soot and toxic/ combustible volatiles for temperature between 300-400 ${ }^{0} \mathrm{C}$. Compared to wet lay-up epoxy-resin applications, TRM strengthening costs are lower due to the low-cost cement mortars utilized. Another disadvantage of FRP is that they are usually manufactured and applied in strips. This effectively results in regions of increased strength and stiffness within the retrofitted structure. In the case of brittle URM structures, this results in stress concentrations in the unreinforced regions that accelerate damage rather than mitigating it [18]. Bati and Rovero [19] demonstrated that when the distance between the FRP strips applied at the extrados is reduced, the resulting ultimate displacements increase, thus resulting in an overall increase of the pseudo-ductility of the virgin masonry wall. The advantages of global rather than stripped strengthening solutions for the case of masonry have been further examined and substantiated in the literature, see, e.g., [20, 58].

In view of the aforementioned, an innovative mineral-based composite material, i.e., textilereinforced mortar (TRM), has been proposed for structural retrofitting, addressing also cost effectiveness and durability issues. TRM comprises layers of textiles made of e.g. highstrength carbon, glass or basalt fibres impregnated within inorganic matrices, such as cementbased mortars. The acronym 'FRCM' is also used in the literature for the same material ([53], [59], [60], [61]). The textiles typically consist of fibre rovings in at least two orthogonal directions, thus creating an open-mesh geometry. Due to the use of mineral-based mortars TRM offers resistance at temperatures of up to $250{ }^{\circ} \mathrm{C}[21,62]$ or even $400^{\circ} \mathrm{C}$ [63], compatibility with concrete and masonry substrates [22], ability to be applied on wet surfaces and low temperatures, and air permeability.

TRM has been used as a strengthening and seismic retrofitting material for reinforced concrete, see, e.g., [21]. A number of experimental studies have been performed to investigate the in-plane response of TRM strengthened masonry walls, see, e.g., [23-32]. Prota et al. [25] studied the in-plane response of tuff masonry panels strengthened with cementitious grid system. Papanicolaou et al. [26] tested TRM strengthened hole clay-brick masonry walls under cyclic in-plane loading and Bernat et al. [28] examined the in-plane compressive eccentric load of solid clay brick masonry walls. Increase of strength and deformability was achieved after applying the composite material in each strengthening configuration. In addition, bond between the TRM material and masonry was investigated by Faella et al. [33], D'Ambrisi et al. [34], and De Felice et al. [49]. The effectiveness of TRM, was also investigated in few experimental studies reported for strengthened masonry arches at 
1 the extrados of the arch with the TRM composite material [35, 36, 50]. Analytical models 2 have also been developed to further highlight the mechanical response of TRM strengthened 3 systems, see, e.g., [37, 38].

Previous experimental studies on the out-of-plane behaviour of masonry walls highlighted the substantial gain in strength and deformability due to TRM strengthening. In particular, Kolsch [39] examined the performance of masonry walls strengthened with three layers of a unidirectional carbon fabric under cyclic loading. The author demonstrated that such an approach prevents the partial or complete collapse of the strengthened structure. Papanicolaou et al. [40] further investigated the influence of the number of carbon fibre textile layers, namely 1 and 2, on the cyclic response of masonry walls strengthened with TRM. It was observed that such a configuration resulted in a shear-flexure failure mode followed by debonding at the brick-bed joint interface. Increasing the number of layers has been found to result in a $25 \%$ increase of the maximum load. Furthermore, Papanicolaou et al. [23] demonstrated the superior performance of coated textile TRM systems by investigating the out-of-plane cyclic performance of masonry walls strengthened with one layer of coated glass, basalt, and coated basalt TRM. Both coated glass and coated basalt specimens demonstrated superior performance by avoiding textile slipping that was the predominant mode of failure in the non-coated basalt specimens.

Harajli et al. [41] studied the out-of-plane response of masonry walls strengthened with a single layer of coated glass and coated/ uncoated basalt textile TRM under both monotonic and cyclic loading. The coated glass textile TRM demonstrated improved performance in terms of load capacity due to the resulting uniform strain distribution. Conversely, in the uncoated basalt fibre textile a single predominant crack was formed leading to the local fracture of the textile. The advantages of utilizing coated textile fibres have also been highlighted in Donnini et al. [51]. In the experimental work undertaken by Tetta et al. [42] in TRM strengthening of reinforced concrete beams, it had been demonstrated that increasing the number of textile layers significantly improves the textile performance by activating a larger ratio of their corresponding tensile strength. In the present study this strategy is further enhanced and applied for the out-of-plane strengthening of masonry walls.

Babaeidarabad et al. [43] further examined the out-of-plane cyclic loading on masonry walls strengthened with one and four layers of carbon textile TRM. The authors demonstrated that for lower reinforcement ratios the dominant failure mode was textile rupture, whereas for high reinforcement ratios shear failure preceded flexural failure. Valluzzi et al. [44] also reported that their strengthening configuration utilizing basalt TRM composite resulted in shear failure mode of the examined masonry walls, whereas tensile fibre rupture was observed in the case of glass textile TRM strengthening. Very recently, Martins et al. [45] proposed an innovative textile configuration comprising either carbon or glass braided composited rods (BCR). The authors demonstrated that such an approach resulted in pure flexure failure mode of the glass BCR and a combined shear-flexure failure mode for the carbon BCR composite material.

This paper investigates for the first time in a systematic way the effect of a series of parameters on the out-of-plane response of masonry walls. In terms of textile reinforcement, both the textile material and the number of textile layers are considered as experimental parameters. Within this setting, a systematic study on the comparative effectiveness of glass, coated basalt and in addition carbon textile reinforcement is undertaken on the basis of utilizing textile layers of equivalent elastic stiffness. More specifically, the influence of 3 and 
17 layers of glass and coated basalt TRM material is examined and their response is directly 2 compared to the 1 layer of carbon fibre TRM case. To the authors' knowledge such a 3 comparative study has not been performed. Furthermore, the effect of the resin coating on carbon and glass strengthened specimens is investigated. The behaviour of resin coated carbon textile has not been examined in the literature. Finally, both single and double-wythe walls are examined.

This work is organized as follows. In Section 2, the experimental program is thoroughly described and the properties of the materials used are presented. Next, the experimental results are presented in Section 3. Discussion of the experimental results is provided in Section 4, and the conclusions drawn are summarised in Section 5.

\section{Experimental Program}

\subsection{Test specimens and investigated parameters}

The main aim of this experimental investigation was to examine the performance of brick masonry walletes strengthened with TRM composite material when subjected to out-of-plane bending. The investigation was carried out in two sets of single and double-wythe walls. Eighteen masonry brick walls in total were constructed (nine single and nine double-wythe) with dimensions of $1340 \times 440 \times 102.5 \mathrm{~mm}$, in a running bond pattern. Medium-scale specimens were built as these are more representative of real walls; this further adds confidence to the test outcomes (i.e. failure modes etc.), [see also 23, 44, 45]. A general purpose masonry cement mortar of approximately $10 \mathrm{~mm}$ thickness was used for both the bed and head joints.

The key investigated parameters of this study were: (a) the number of TRM layers, (b) the textile-fibre material, namely carbon, glass and coated basalt (c) the epoxy-resin coating, and (d) the wall thickness (single and double-wythe). Two specimens built to serve as control specimens, one for single (S_CON) and one for double-wythe walls (D_CON), respectively. The remaining 16 specimens were strengthened at the tensile wall face with the objective of improving their out-of-plane flexural performance. A single TRM layer was considered for the case of carbon-fibre textiles, whereas 3 and 7 layers were examined for the case of both glass-fibre and coated basalt-fibre textiles.

The wall specimens with their corresponding parameters are shown in Table 1. The strengthening configuration is shown in Fig. 1a while the actual test setup is shown in Fig. $1 \mathrm{~b}$. The notation considered for the strengthened specimens is $\mathrm{W} \_\mathrm{XN}$, where $\mathrm{W}$ denotes the single or double-wythe walls ( $\mathrm{S}$ for single and $\mathrm{D}$ for double-wythe wall), $\mathrm{X}$ denotes the type of the textile ( $\mathrm{C}$ for carbon, $\mathrm{G}$ for glass and $\mathrm{B}$ for coated basalt) and $\mathrm{N}$ denotes the number of layers (1, 3 and 7). The suffix Co denotes textiles coating with epoxy resin.

\subsection{Materials}

Solid clay bricks were used with UK typical nominal dimensions of 215 x 102.5 x $65 \mathrm{~mm}$. The clay brick compressive strength was obtained from compression tests applied on the bed and stretcher faces with dimensions $215 \times 102.5 \mathrm{~mm}$ and $215 \times 65 \mathrm{~mm}$, respectively per BS EN 772-1 (2011) [57]. Its corresponding mean value was $21.2 \mathrm{MPa}$. A 1:4 cement to sand mix was utilised for both head and bed joint mortar. The amount of water was defined through trial mixes, until the desired workability was achieved. In all cases, it was ensured that water to (cement + sand) ratio was constant and equal to 0.25 . 
Table 1 Wall Specimens

\begin{tabular}{llcccc}
\hline Specimen & Wythe & $\begin{array}{c}\text { TRM } \\
\text { material }\end{array}$ & Number of TRM Layers & $\begin{array}{c}\text { TRM } \\
\text { thickness } \\
\text { [mm] }\end{array}$ & Coating \\
\hline S_CON & Single & & $\begin{array}{c}\text { Unstrengthened Control } \\
\text { Specimen }\end{array}$ & \\
\hline D_CON & Double & & $\begin{array}{c}\text { Unstrengthened Control } \\
\text { Specimen }\end{array}$ & \\
\hline S_C1 & Single & Carbon & 1 & 3 & No \\
\hline S_C1_(Co) & Single & Carbon & 1 & 5 & Yes \\
\hline S_G3 & Single & Glass & 3 & 4 & No \\
\hline S_G3_(Co) & Single & Glass & 3 & 7 & Yes \\
\hline S_G7 & Single & Glass & 7 & 8 & No \\
\hline S_G7_(Co) & Single & Glass & 7 & 9 & Yes \\
\hline S_B3 & Single & Coated basalt & 3 & 13 & No \\
\hline S_B7 & Single & Coated basalt & 7 & 3 & No \\
\hline D_C1 & Double & Carbon & 1 & 5 & Yes \\
\hline D_C1_(Co) & Double & Carbon & 1 & 4 & No \\
\hline D_G3 & Double & Glass & 3 & 7 & Yes \\
\hline D_G3_(Co) & Double & Glass & 3 & 8 & No \\
\hline D_G7 & Double & Glass & 7 & 9 & Yes \\
\hline D_G7_(Co) & Double & Glass & 7 & 9 & No \\
\hline D_B3 & Double & Coated basalt & 3 & 13 & No \\
\hline D_B7 & Double & Coated basalt & 7 & & \\
\hline
\end{tabular}

3 For each individual wall specimen, the flexural and compressive strength of both the joint 4 and strengthening mortar was identified by conducting a series of three-point bending and 5 compressive strength experiments on $40 \times 40 \times 160 \mathrm{~mm}$ prisms per the EN 1015-11 (1993)

6 specifications [46]. Three prisms were tested in three-point bending, whereas the compressive 7 strength was established through uniaxial compression tests on the ruptured parts of the 8 flexural test prisms. The bearing surface of the latter was $40 \times 40 \mathrm{~mm}$. The mean values of 9 the corresponding quantities together with their standard deviation and the coefficient of 10 Variation for the case of single and double-wythe walls are summarized in Table 2. The 11 casting mortar demonstrates higher variability in its corresponding compressive and tensile 12 strength than the strengthening mortar. It should be highlighted that such variability does not 13 significantly affect the results in terms of the reported failure modes.

14 The compressive strength of the masonry was determined in a direction perpendicular to the 15 bed joints according to the EN 1052-1 (1998) [54]. Three compressive tests on masonry 16 assemblages of dimensions 450x450x65 mm (length $\mathrm{x}$ height $\mathrm{x}$ width) were conducted. Two 17 potentiometers were placed halfway on both sides at a gauge length of $250 \mathrm{~mm}$, to record the 18 deformation of the wall. Tests were conducted after 28 days of their construction. The mean 19 value of the compressive strength obtained from the experimental data was 9.7 MPa. The 20 secant elastic modulus was determined accordingly at 0 to $30 \%$ of the maximum stress to be 21 equal to $2.5 \mathrm{GPa}$.

22 Three different materials were used, namely the carbon-fibre textile (either uncoated or 23 coated with epoxy resin), the glass-fibre textile (uncoated or coated with epoxy resin) and the 24 coated basalt-fibre textile. The different textile configurations are shown in Fig. 2. The 
material properties of the textile materials considered, as provided in the manufacturer datasheets are presented in Table 3. Tensile stress and Young's modulus correspond to fibres, whereas weight and nominal thickness to the textile. In particular, nominal thickness was estimated based on the equivalent smeared distribution of fibres.

The coated basalt fibre-textile employed in this study is a commercial product fabricated with a bituminous binder of $10 \%$ content. The coated carbon and glass fibre textiles were impregnated in a commercial epoxy adhesive (two-part epoxy resin with a mixing ratio 2:1 by weight). The epoxy resin elastic modulus was $1.8 \mathrm{GPa}$ and the tensile strength was 37 $\mathrm{MPa}$ (according to the manufacturer datasheets). The impregnation of the dry glass and carbon fibre-textile was performed using a plastic roll and then left to cure for two days before strengthening application. The holes of the mesh remained opened after the coating procedure. The average amount of the epoxy resin used for the impregnation was $180 \mathrm{~g} / \mathrm{m}^{2}$.

As shown in Table 1, five strengthening configurations were investigated in this experimental program, i.e., 1 layer of carbon-fibre textile (uncoated and coated), 3 and 7 layers of glassfibre textile (uncoated and coated) and 3 and 7 layers of coated basalt-fibre textile, for both single and double walls. The number of 7 glass-fibre layers has been chosen on the basis of the axial stiffness similarity principle also utilised in [47]. The 7-layer glass and basalt fibre to single layer carbon axial stiffness ratio is readily derived from the following expression

$$
\frac{n_{l, g} t_{g} E_{f, g}}{n_{l, c} \cdot t_{c} E_{f, c}}=\frac{7 \cdot 0.044 \cdot 74}{1 \cdot 0.097 \cdot 225}=1.04
$$

where $n_{l, g}$ is the number of glass fibre TRM layers, $t_{g}$ is the nominal thickness of the glass textile, $E_{f, g}$ is the elastic modulus of the glass fibres, $n_{l, c}$ is the number of carbon fibre TRM layers, $t_{c}$ is the carbon textile thickness and $E_{f, c}$ is the carbon modulus of elasticity. In case of coated basalt fibre textile the corresponding ratio is equal to 1.06 . Thus, a direct comparison of the strengthening performance of the three materials utilised can be achieved as discussed in Section 4.

The cement-based mortar used during the TRM composite system application, between the textile and the masonry substrate, was an inorganic dry binder comprising cement and polymers at a ratio 8:1 by weight. Strength properties of this mortar were obtained by similar procedure, followed for the mortar used for the brick walls construction. The mean values of flexural and compressive strength on the day of testing were 8.9 $\mathrm{MPa}$ and $39.7 \mathrm{MPa}$, respectively. The water to cementitious material ratio adopted was 0.23 by weight.

Compatibility between the mortar matrix material and the textile fibre reinforcement has been investigated and the advantages of using appropriate mortar mixes for different textile fibre materials have been documented, see, e.g., [28], [41]. In this work, the same mortar was employed for all specimens with the objective of providing a comparable basis with respect to the investigated parameters of interest, i.e., the effect of the textile material, the number of TRM layers, the epoxy resin coating of the textile, and the wall thickness. 


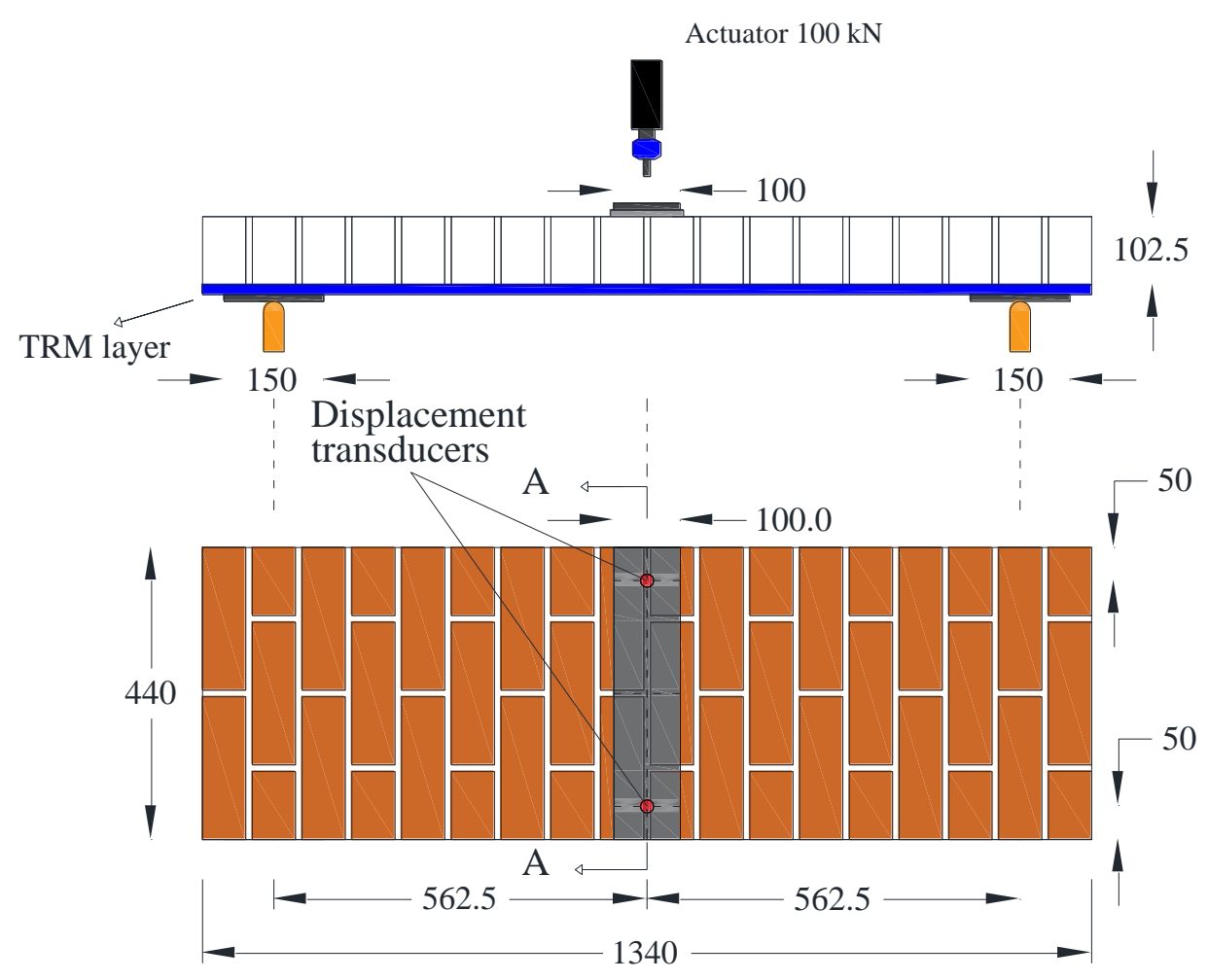

(a)

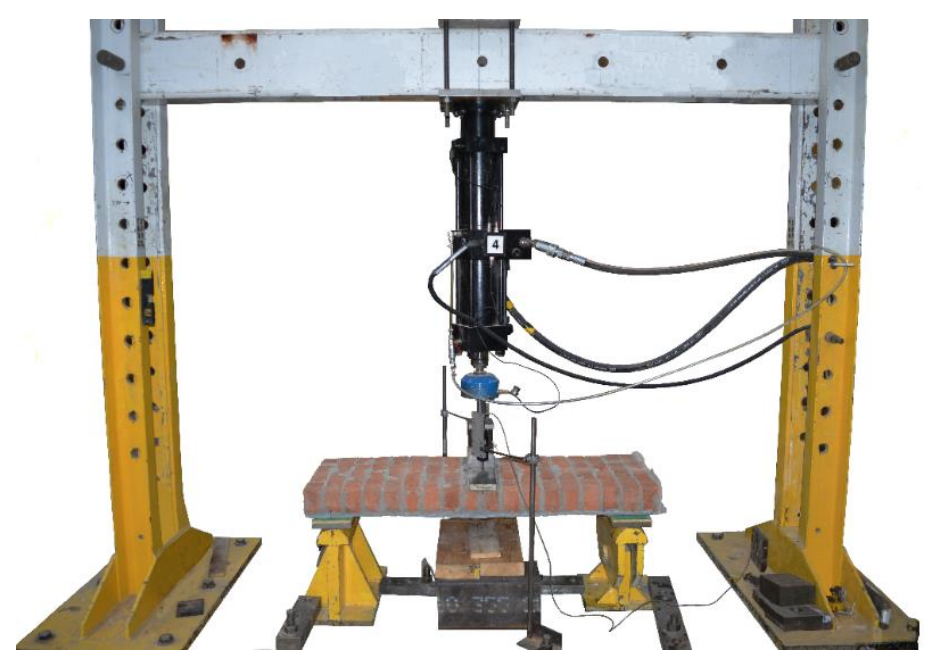

(b)

1 Fig. 1 Experimental setup; (a) plan view and elevation (all dimensions in mm) (b) actual 2 setup 
Table 2 Casting and strengthening mortar

\begin{tabular}{|c|c|c|c|c|c|}
\hline & \multirow[t]{2}{*}{ Specimens } & \multicolumn{2}{|c|}{ Casting mortar } & \multicolumn{2}{|c|}{ Strengthening mortar } \\
\hline & & $\begin{array}{c}\text { Compressive } \\
\text { Strength } \\
{[\mathrm{MPa}]} \\
\end{array}$ & $\begin{array}{c}\text { Tensile } \\
\text { Strength } \\
{[\mathrm{MPa}]} \\
\end{array}$ & $\begin{array}{c}\text { Compressive } \\
\text { Strength } \\
{[\mathrm{MPa}]} \\
\end{array}$ & $\begin{array}{c}\text { Tensile } \\
\text { Strength } \\
{[\mathrm{MPa}]} \\
\end{array}$ \\
\hline \multirow{10}{*}{ 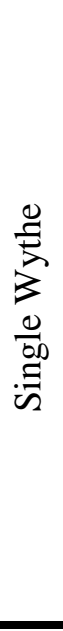 } & S_CON & 8.09 & 2.06 & - & - \\
\hline & S_C1 & 6.54 & 1.99 & 38.36 & 10.19 \\
\hline & S_C1_(Co) & 8.86 & 2.26 & 37.30 & 8.20 \\
\hline & S_G3 & 6.54 & 1.99 & 38.36 & 10.19 \\
\hline & S_G3_(Co) & 8.86 & 2.26 & 37.25 & 7.98 \\
\hline & S_G7 & 7.73 & 1.99 & 37.39 & 8.70 \\
\hline & S_G7_(Co) & 10.30 & 2.36 & 39.69 & 8.88 \\
\hline & S_B3 & 7.73 & 1.99 & 37.39 & 8.70 \\
\hline & S_B7 & 8.09 & 2.06 & 37.30 & 8.20 \\
\hline & Mean value & $\begin{array}{c}7.4 \\
\left(2.3^{*} / 0.31^{* *}\right) \\
\end{array}$ & $\begin{array}{c}1.9 \\
\left(0.5^{*} / 0.26^{* *}\right) \\
\end{array}$ & $\begin{array}{c}37.9 \\
\left(0.9^{*} / 0.02^{* *}\right) \\
\end{array}$ & $\begin{array}{c}8.9 \\
\left(0.9^{*} / 0.10^{* *}\right) \\
\end{array}$ \\
\hline \multirow{10}{*}{ 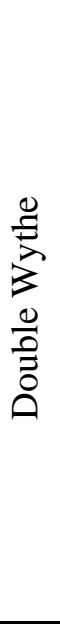 } & D_CON & 9.35 & 3.38 & & \\
\hline & D_C1 & 6.59 & 1.95 & 37.39 & 8.70 \\
\hline & D_C1_(Co) & 6.90 & 2.21 & 41.49 & 8.22 \\
\hline & D_G3 & 6.68 & 2.40 & 46.58 & 11.05 \\
\hline & D_G7 & 6.68 & 2.40 & 46.58 & 11.05 \\
\hline & D_G3_(Co) & 9.35 & 3.38 & 41.49 & 8.22 \\
\hline & D_G7_(Co) & 8.29 & 2.41 & 37.30 & 8.20 \\
\hline & D_B3 & 6.90 & 2.21 & 41.49 & 8.22 \\
\hline & D_B7 & 6.90 & 2.21 & 40.43 & 8.34 \\
\hline & Mean value & $\begin{array}{c}7.5 \\
\left(1.2^{*} / 0.16^{* *}\right)\end{array}$ & $\begin{array}{c}2.5 \\
\left(0.5^{*} / 0.20^{* *}\right)\end{array}$ & $\begin{array}{c}41.6 \\
\left(3.5^{*} / 0.08^{* *}\right)\end{array}$ & $\begin{array}{c}9.0 \\
\left(1.3^{*} / 0.14^{* *}\right)\end{array}$ \\
\hline
\end{tabular}

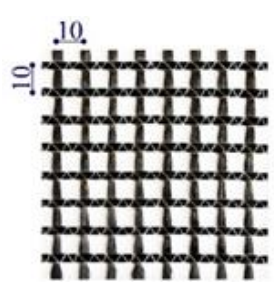

(a) Carbon

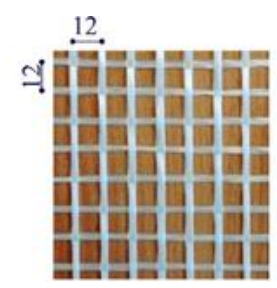

(b) Glass

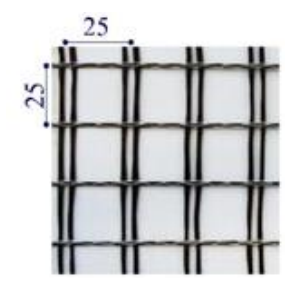

(c) Coated Basalt

Fig. 2 Textiles used in this study 


\section{$1 \quad 2.3 \quad$ Strengthening procedure}

2 The TRM application procedure involved the following steps:

3 1. Air pressure was used to remove dust from the masonry wall surfaces to be strengthened with the TRM composite.

2. The wall was slightly dampened and a first layer of mortar was applied at the whole surface of the wall (Fig. 3a).

3. The first textile layer was applied and impregnated into the previously applied mortar layer using hand pressure (Fig. 3b). It is noted that in all specimens, the textile covered the entire brick wall surface to be subjected in tension.

4. Application of a final layer of mortar to completely cover the textile. For multiple strengthening layers the procedure of alternate textile and mortar layer was repeated. The procedure was completed while the mortar was fresh to achieve optimum adhesion of the

Table 3 Textile material properties

\begin{tabular}{|c|c|c|c|c|c|}
\hline $\begin{array}{c}\text { Material } \\
{[/]} \\
\end{array}$ & $\begin{array}{c}\text { Weight } \\
{\left[\mathrm{g} / \mathrm{m}^{2}\right]} \\
\end{array}$ & $\begin{array}{c}\text { Thickness } \\
\text { (Nominal) } \\
{[\mathrm{mm}]} \\
\end{array}$ & $\begin{array}{c}\text { Tensile Strength } \\
{[\mathrm{MPa}]} \\
\end{array}$ & $\begin{array}{c}\text { Young's } \\
\text { modulus } \\
\text { [GPa] } \\
\end{array}$ & $\begin{array}{c}\text { Axial Stiffness for a } \\
\text { Single Layer } \\
{[\mathrm{N} / \mathrm{mm}]^{*}} \\
\end{array}$ \\
\hline Heavy Carbon & 348 & 0.097 & 3800 & 225 & 21.83 \\
\hline Glass & 220 & 0.044 & 1400 & 74 & 3.26 \\
\hline Coated basalt & 220 & 0.037 & 1351 & 89 & 3.30 \\
\hline
\end{tabular}
TRM layers. The final strengthened configuration is presented in Fig. 3c.

* calculated as the nominal thickness to Young's modulus product

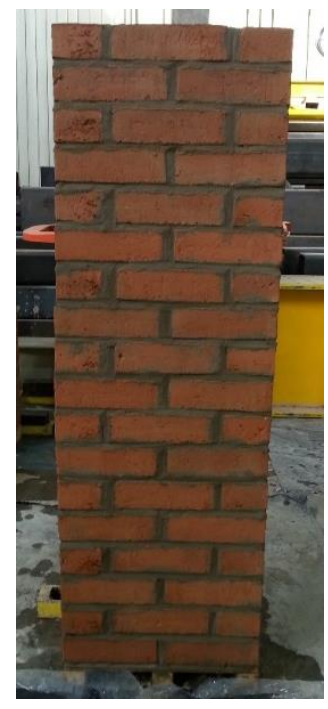

(a)

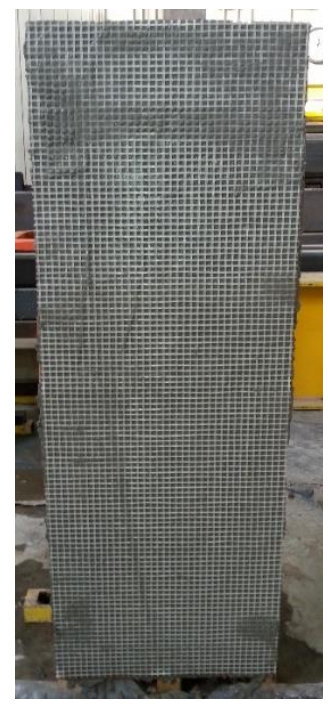

(b)

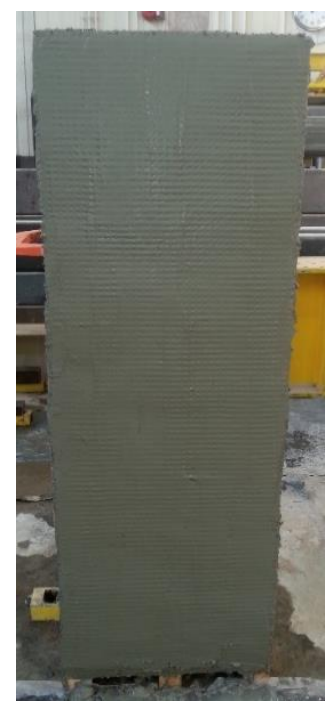

(c)

Fig. 3 (a) Dampening of the wall (b) application of glass textile layer into the mortar (c) application of the final layer of mortar

18 In actual infill applications, it is recommended to leave some margins around the 19 strengthened surface to prevent stress concentrations, see, e.g. [49]. In this experimental 
work, such a provision was not made as no stress concentrations were expected at the free boundaries of the specimen.

\subsection{Experimental setup and procedure}

A three-point-bending loading configuration was adopted for the out-of-plane tests of the masonry walls, resulting in an effective span of $1125 \mathrm{~mm}$, as shown in Fig. 1a. The supports were spaced $107.5 \mathrm{~mm}$ from the ends of the masonry wall. The test setup consisted of a stiff steel reaction frame fastened with a vertically positioned actuator as shown in Fig. 1b. A 100 $\mathrm{kN}$ capacity servo-hydraulic actuator, used for the load application at a displacement rate equal to $0.017 \mathrm{~mm} / \mathrm{s}$ (i.e., $1 \mathrm{~mm} / \mathrm{min}$ ). Two potentiometers were used to measure the out-ofplane displacement at mid-span. The transducers were placed at a distance of $50 \mathrm{~mm}$ from each side of the wall, as shown in Fig. 1a. Data was collected at a frequency of $4 \mathrm{~Hz}$, synchronised and recorded using a fully-computerized data acquisition system.

\section{Experimental results}

The load versus out-of-plane deflection curves for all tests are presented in Fig. 4a for the case of single-wythe walls and in Fig. $4 \mathrm{~b}$ for the case of double-wythe walls respectively. The identified key parameters of the experimental results, i.e., the maximum load $\mathrm{P}_{\max }$, the midspan deflection at maximum load, the ultimate load, the midspan deflection at the ultimate load, the ratio of the maximum load to that of the control specimen, and the observed failure modes are summarised in Table 4. The corresponding failure modes are shown in Fig. 6 and Fig. 7 for single- and double-wythe specimens respectively. The ultimate load defined as $\mathrm{P}_{\text {ult }}=\max \left(0.8 \mathrm{P}_{\max }\right.$, final load $)$. Experimental results are further grouped in terms of investigated parameters in Fig. 5 to facilitate discussion in terms of the behaviour observed.

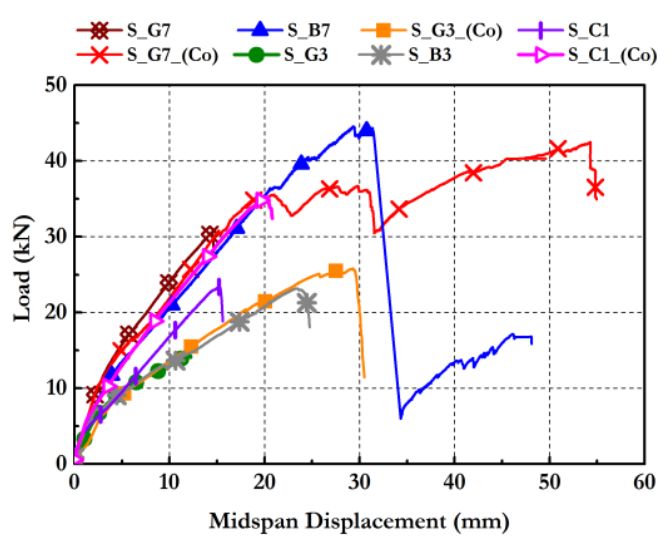

(a)

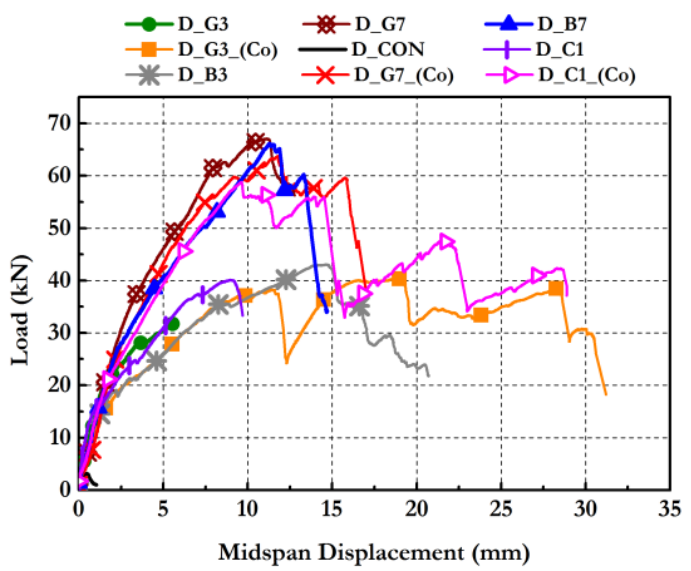

(b)

Fig. 4 Experimental load-displacement response curves for (a) single-wythe walls, and (b) double-wythe walls

\subsection{Single-wythe walls}

The control specimen failed under the action of its own weight during placement on the testsetup. The nominal strength of the wall, as evaluated from BS EN (1996) [48], is used herein for the sake of comparison; the out-of-plane bending strength $\mathrm{f}_{\mathrm{xk} 1}=0.26 \mathrm{MPa}$ has been derived based on the strength of D_CON and agrees well with the suggested values provided in BS EN (1996) [48]. All strengthened specimens demonstrated significantly increased maximum 
and ultimate loads as compared to the control specimen. Out of the strengthened specimens, S_G3 demonstrated the lowest value of all recorded maximum load $\left(\mathrm{P}_{\max }=14.3 \mathrm{kN}\right)$ whereas the highest value was recorded for specimen $\mathrm{S} \_\mathrm{B} 7\left(\mathrm{P}_{\max }=44.5 \mathrm{kN}\right)$.

The failure mode observed in the strengthened specimens varied, depending on the textile material used, the presence of coating or not and the number of applied layers. The observed failure modes comprised textile rupture (S_C1_(Co), S_G3, S_G3_(Co), S_G7, S_B3), slippage of the textile fibres through the mortar (S_C1), and shear failure of the masonry wall (S_G7_(Co), S_B7) as shown in Table 4. Failure modes of all single-wythe specimens are shown in Fig. 6.

10 Mid-span displacements at the maximum load were also substantially increased in all strengthened specimens as compared to the control specimen. The lowest value of mid-span displacement at maximum load was recorded for $\mathrm{S} \_\mathrm{G} 3\left(\mathrm{~d}_{\max }=12.1 \mathrm{~mm}\right)$ whereas the highest recorded value was for S_G7_(Co) $\left(\mathrm{d}_{\max }=54.3 \mathrm{~mm}\right)$. Specimens S_G7_(Co) and S_B7 that failed in shear demonstrated a highly pseudo-ductile behaviour (Fig. 4a).

\subsection{Double-wythe walls}

The control specimen D_CON failed in flexure in an abrupt and brittle fashion. The maximum load and corresponding displacement was $3.1 \mathrm{kN}$ and $1 \mathrm{~mm}$, respectively. As in the case of the single wythe specimens, strengthened double wythe specimens demonstrated a significantly improved response with respect to their maximum attained loads and corresponding deflections. As shown in Table 4, specimens D_G7, D_G7_(Co), and D_B7 demonstrated the highest increase in maximum attained load which was on average 21 times the maximum load of D_CON.

The observed failure loads were textile rupture (D_C1, D_G3), diagonal tension (D_B7), shear flexure followed by TRM debonding (D_G3_(Co), D_G7_(Co)), shear-flexure followed by textile rupture (D_G7), and shear-flexure followed by brick sliding and partial textile rupture (D_C1_(Co), D_B3). Failure modes of all single-wythe specimens are shown in Fig. 7.

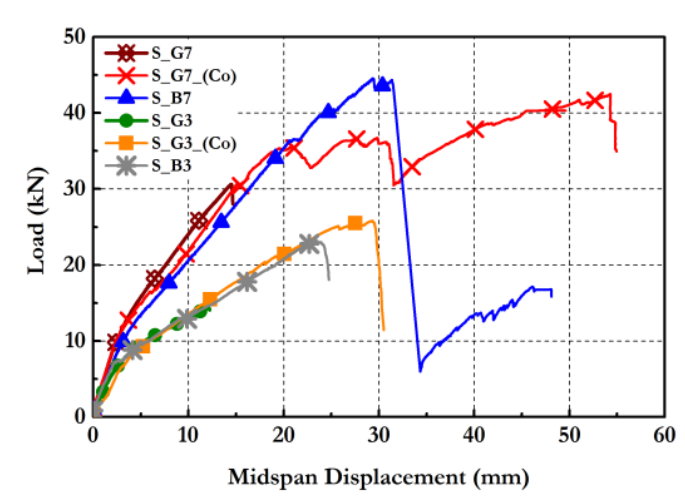

(a) Single-wythe walls: three vs seven textile layers

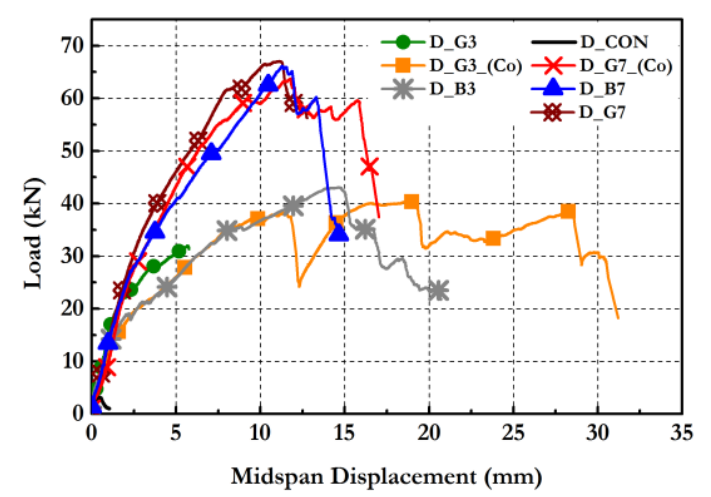

(b) Double-wythe walls: three vs seven textile layers 


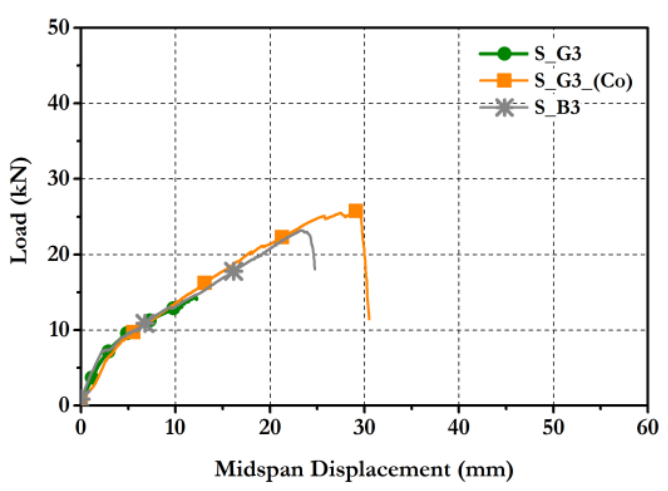

(c) Single-wythe walls: three layers of textile

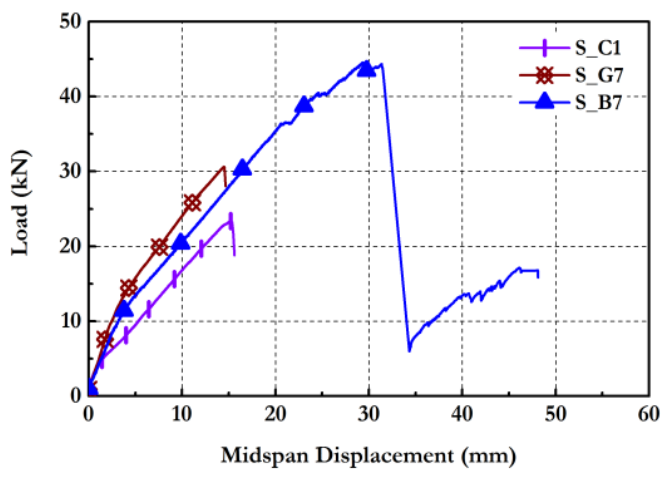

(e) Single-wythe walls: one layer of carbon fibre textile vs seven layers of glass and coated basalt textile

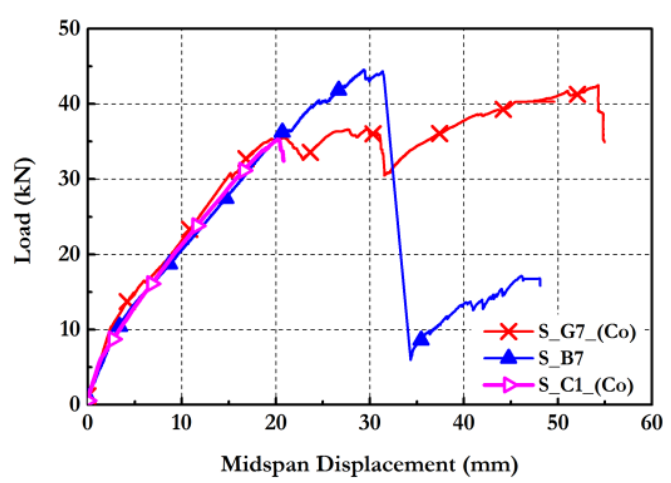

(g) Single-wythe walls: one layer of carbon coated fibre textile vs seven layers of glass coated and coated basalt textile

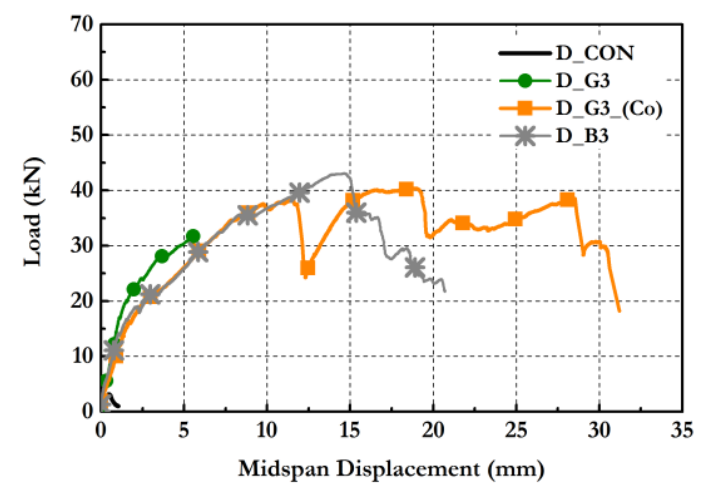

(d) Double-wythe walls: three layers of textile

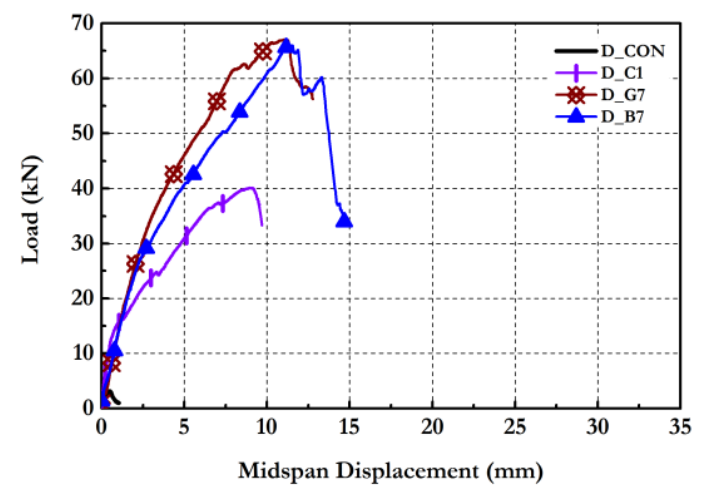

(f) Double-wythe walls: one layer of carbon fibre textile vs seven layers of glass and coated basalt textile

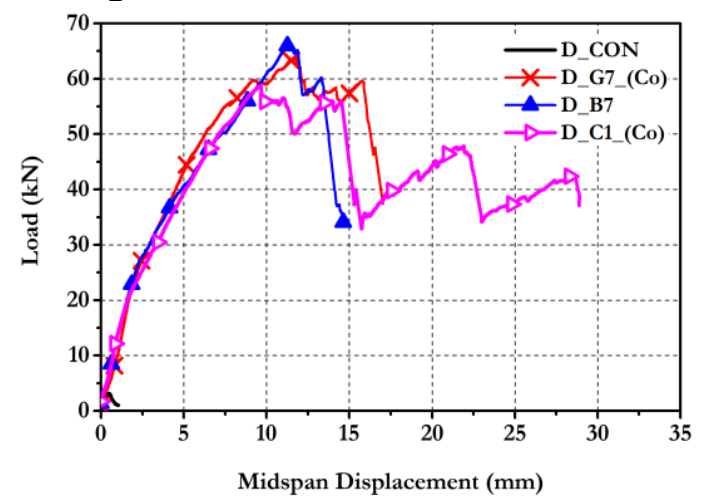

(h) Double-wythe walls: one layer of carbon coated fibre textile vs seven layers of glass coated and coated basalt textile

Fig. 5 Experimental load-displacement response curves grouped in terms of investigated 


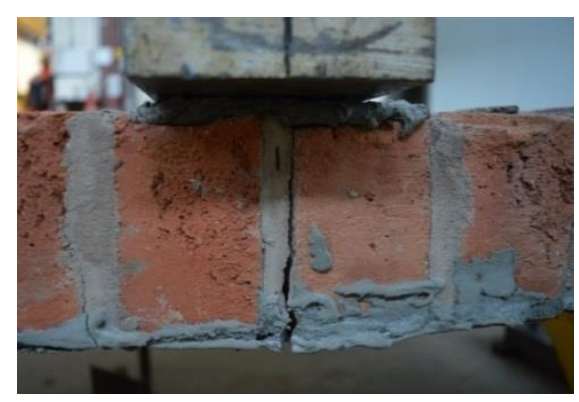

(a) $\mathrm{S}+\mathrm{C} 1$

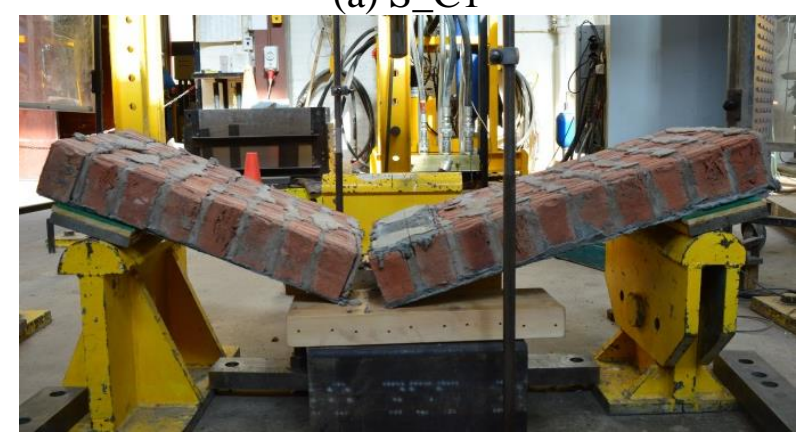

(c) S_G3

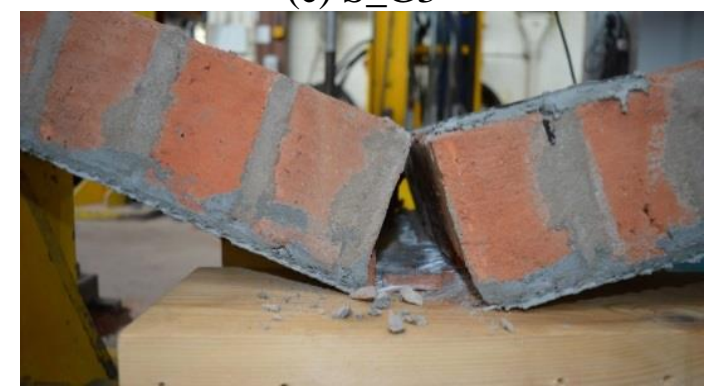

(e) S_G7

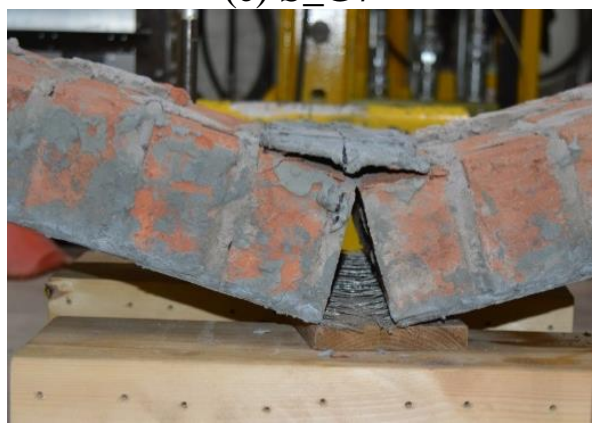

(e) S_B3

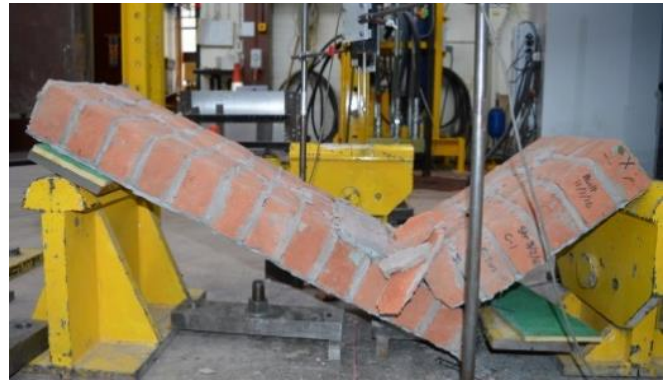

(b) S_C1_(Co)

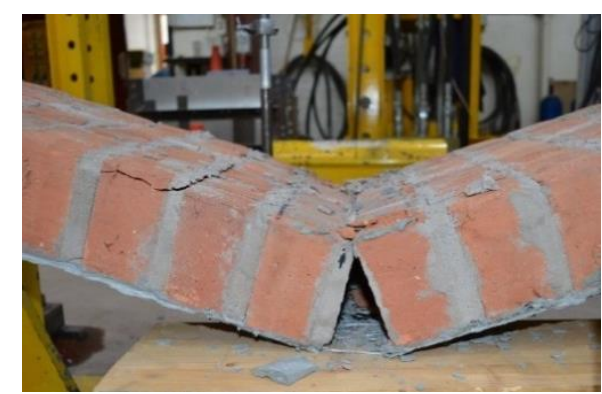

(d) S_G3_(Co)

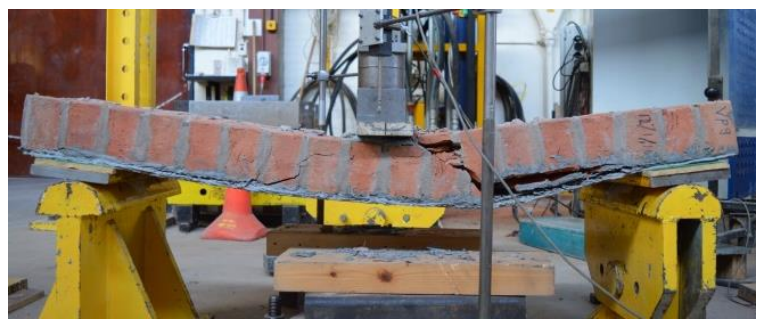

(f) S_G7_(Co)

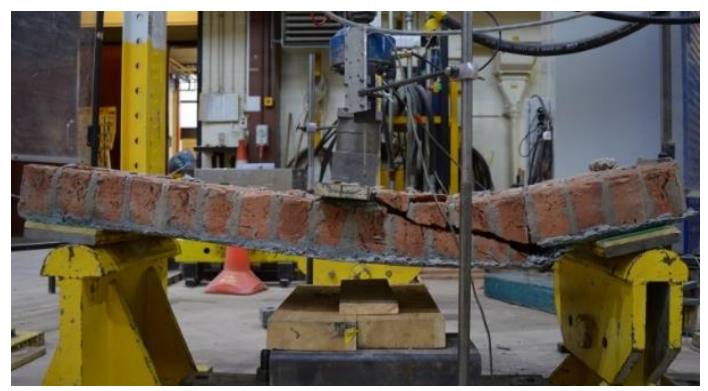

(f) S_B7 Fig. 6 Failure modes of single-wythe specimens 


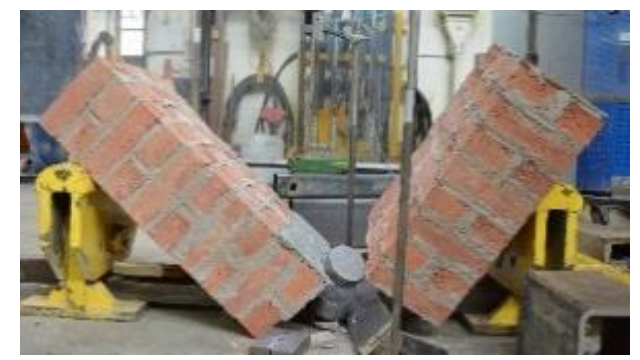

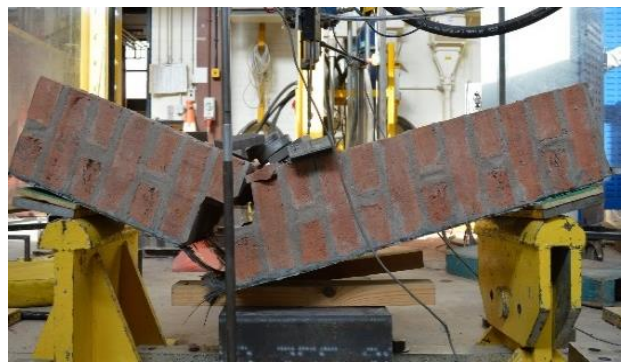

(b) D_C1

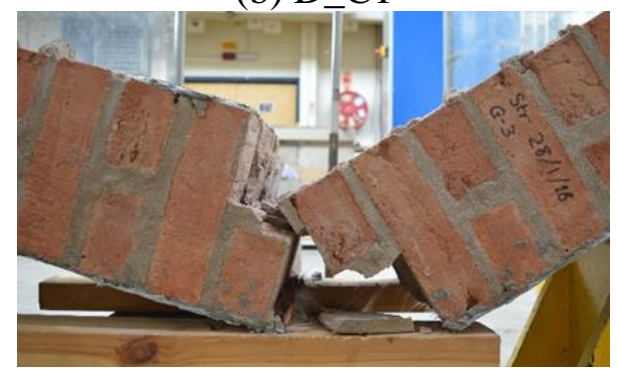

(d) D_G3

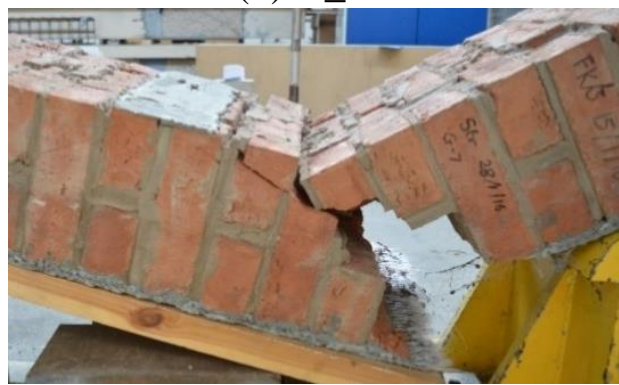

(f) D_G7

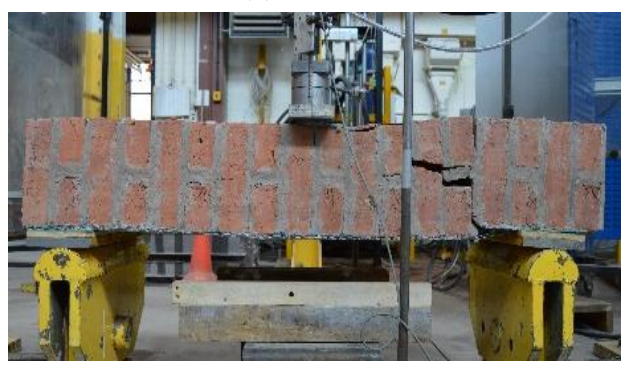

(h) D_B3

(a) D_CON

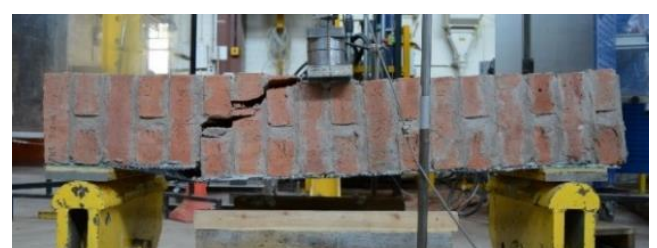

(c) D_C1_(Co)

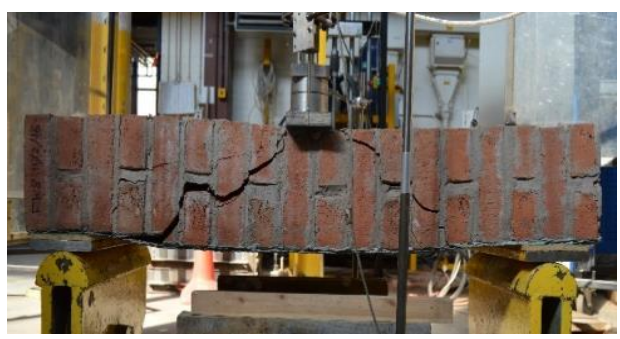

(e) D_G3_(Co)

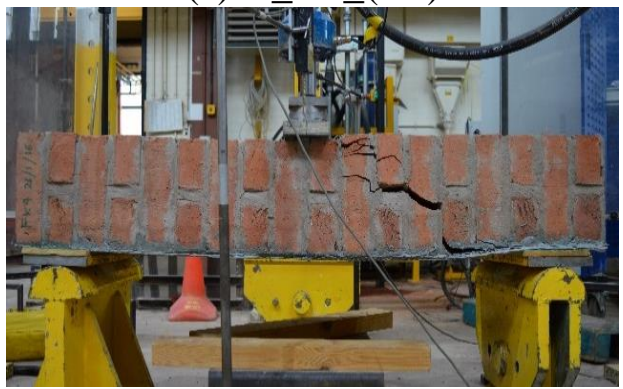

(g) D_G7_(Co)

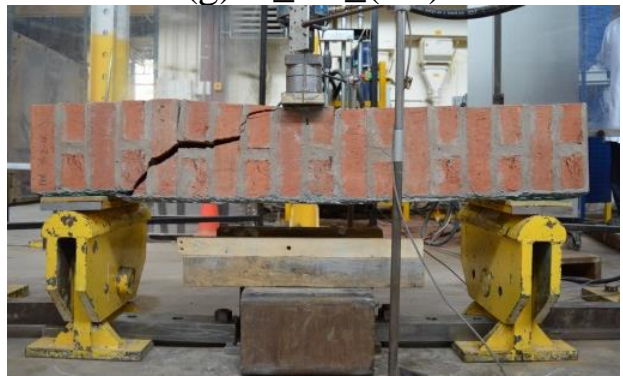

(i) D_B7

Fig. 7 Failure modes of double-wythe specimens 
Table 4 Summary of experimental results

\begin{tabular}{|c|c|c|c|c|c|c|c|}
\hline & & $\begin{array}{c}\text { Maximum } \\
\quad \text { load } \\
\mathbf{P}_{\max } \\
\end{array}$ & $\begin{array}{c}\text { Midspan Deflection } \\
\text { at maximum load } \\
d_{\max } \\
\end{array}$ & $\begin{array}{c}\text { Ultimate } \\
\text { load } \\
\mathbf{P}_{\text {ult }} \\
\end{array}$ & $\begin{array}{c}\text { Ultimate midspan } \\
\text { deflection } \\
d_{\text {ult }} \\
\end{array}$ & $\mathbf{P}_{\max } / \mathbf{P}_{\text {con }}$ & Failure mode \\
\hline & & {$[\mathbf{k N}]$} & {$[\mathrm{mm}]$} & {$[\mathrm{kN}]$} & {$[\mathrm{mm}]$} & & \\
\hline \multirow{9}{*}{ 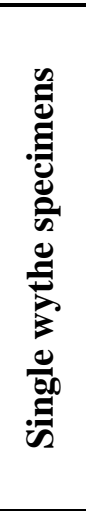 } & S_CON & $0.7 *$ & & & & 1.0 & Failed under its own weight \\
\hline & S_C1 & 23.4 & 15.2 & 18.8 & 15.6 & 33.4 & $\begin{array}{l}\text { Slippage between textile } \\
\text { fibres-mortar }\end{array}$ \\
\hline & S_C1_(Co) & 35.3 & 20.1 & 32.4 & 20.8 & 50.4 & Textile rupture \\
\hline & S_G3 & 14.3 & 12.1 & 14.1 & 12.2 & 20.4 & Textile rupture \\
\hline & S_G3_(Co) & 25.8 & 29.3 & 20.6 & 30.0 & 36.9 & Textile rupture \\
\hline & S_G7 & 30.6 & 14.5 & 28.0 & 14.7 & 43.7 & Textile rupture \\
\hline & S_G7_(Co) & 42.5 & 54.3 & 35.0 & 55.0 & 60.7 & Shear failure ${ }^{1}$ \\
\hline & S_B3 & 23.2 & 23.3 & 18.6 & 24.7 & 33.1 & Textile rupture \\
\hline & S_B7 & 44.5 & 29.3 & 35.6 & 32.1 & 63.6 & Shear failure ${ }^{1}$ \\
\hline \multirow{9}{*}{ 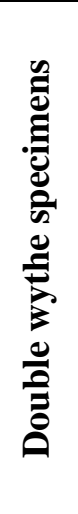 } & $\mathrm{D} \_\mathrm{CON}$ & 3.1 & 0.5 & 2.5 & 0.6 & 1.0 & \\
\hline & D_C1 & 40.1 & 9.0 & 33.3 & 9.7 & 12.9 & Textile rupture \\
\hline & D_C1_(Co) & 58.8 & 9.7 & 47.0 & 14.9 & 19.0 & Shear-flexure ${ }^{4}$ \\
\hline & D_G3 & 32.0 & 5.7 & 31.3 & 5.8 & 10.3 & Textile rupture \\
\hline & D_G3_(Co) & 40.4 & 18.9 & 32.3 & 28.8 & 13.0 & Shear-flexure ${ }^{2}$ \\
\hline & D_G7 & 67.1 & 11.2 & 56.3 & 12.8 & 21.6 & Shear-flexure ${ }^{3}$ \\
\hline & D_G7_(Co) & 63.8 & 11.8 & 51.0 & 16.2 & 20.6 & Shear-flexure ${ }^{2}$ \\
\hline & D_B3 & 43.1 & 14.6 & 34.5 & 16.7 & 13.9 & Shear-flexure ${ }^{4}$ \\
\hline & D_B7 & 66.2 & 11.3 & 53.0 & 13.6 & 21.4 & Shear failure ${ }^{1}$ \\
\hline${ }^{*} \mathrm{Calcu}$ & $\begin{array}{l}{ }^{1} \text { Diagonal } \\
\text { tension } \\
\text { ulated from EC } 6\end{array}$ & $\begin{array}{l}{ }^{2} \text { Shear-flexure fo } \\
\text { ased on the value }\end{array}$ & $\begin{array}{l}\text { by debonding of TRM } \\
\text { derived from D_CON }\end{array}$ & ${ }^{3}$ Shear- flexure & $\mathrm{d}$ by textile rupture & $\begin{array}{l}{ }^{4} \text { Shear- flexure follo } \\
\text { rupture }\end{array}$ & d by brick sliding and partial textile \\
\hline
\end{tabular}




\section{$2 \quad 4.1$ The effect of wall thickness}

3 The evaluation of the results obtained is based on the various parameters investigated in this 4 series of experiments. All specimens demonstrated a significant increase in the out-of-plane flexural capacity, compared to their corresponding control specimens. In Fig. 8a, b the strengthened to control specimen maximum load ratios versus the stiffness of the reinforcement layers are plotted for single- and double- wythe walls respectively. An estimated shear capacity normalised to the control specimen maximum load is also shown. Shear capacity was calculated per TMS 402-02 (MSJC 2002) as this provides an estimate more consistent to the experimental results than EC6.

In coated single-wythe specimens, S_B7 demonstrated the highest ratio, i.e., 63.6 times the maximum load of the corresponding control specimen S_CON. The lowest ratio was recorded for specimen S_B3 and was equal to 33.1. Conversely, in uncoated specimens the highest increase was recorded for specimen S_G7, i.e., 43.7, whereas the lowest increase was recorded for specimen S_G3, i.e., 20.4. In double-wythe walls strengthened with uncoated textile fibre materials, the highest and lowest recorded ratios were 21.6 and 10.3 for specimens D_G7 and D_G3 respectively. For the case of coated textile fibre materials, the corresponding ratios were 21.4 for specimen D_B7 and 13 for specimen D_G3_(Co).

Double-wythe walls demonstrated lower ratios when compared to their single-wythe counterparts. The increased thickness of the wall resulted in increased effective depths when compared to the single-wythe specimens thus leading to better utilization of the additional textile reinforcement. Hence, almost in all cases, the maximum load of the strengthened double-wythe specimens was bounded by the masonry shear capacity as shown by the corresponding failure modes reported in Table 4 and Fig. $8 \mathrm{~b}$ where the shear capacity estimate is indeed close to the recorded experimental results.

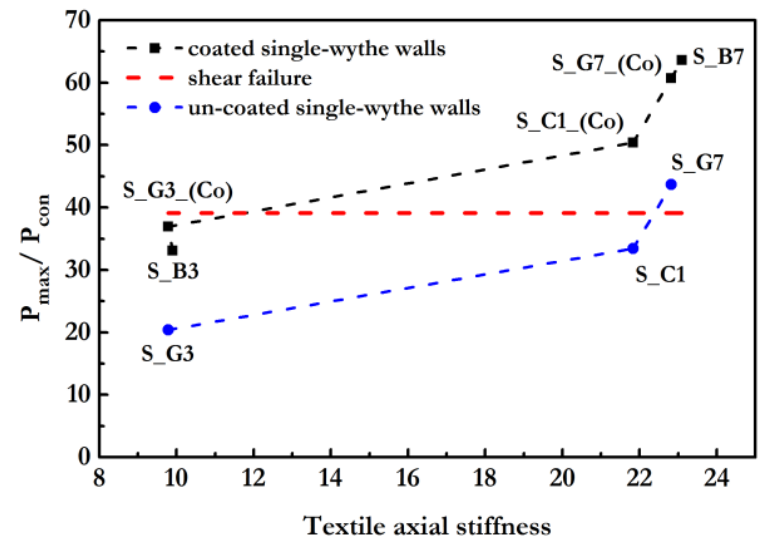

(a)

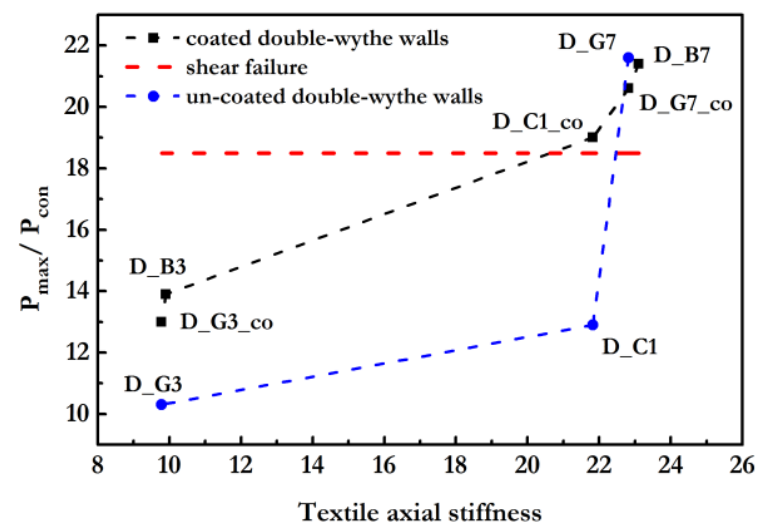

(b)

Fig. 8 Ratio of strengthened specimen maximum load to control specimen maximum load (a) single-wythe walls (b) double-wythe walls

\subsection{The effect of coating}

The effect of coating on the maximum load of the single-wythe specimens is highlighted in Fig. 8a. Specimens S_C1_(Co), S_G3_(Co), and S_G7_(Co) demonstrated increased values 
1 of the maximum load by $51 \%, 81 \%$ and $39 \%$, with respect to their corresponding non-coated 2 counterparts, i.e., S_C1, S_G3, and S_G7, respectively.

3 Specimen S_C1 failed due to slippage of the textile through the mortar contrary to the 4 corresponding coated specimen S_C1_(Co) where failure occurred through tensile rupture of the textile. Although slippage did not occur for the case of the specimens retrofitted with three and seven uncoated glass-fibre textile layers, yet the contribution of the fibre textile in the coated case was significantly enhanced, as manifested by the overall increase in their corresponding maximum strength (see also Fig. 4a). This beneficious impact of coating is attributed to the improved mechanical interlocking conditions obtained through the enhanced stress transfer mechanism from the fibres to the cementitious matrix; this eventually improves the contribution of roving filaments at the time of failure [see also, 22, 23].

With the exception of D_C1_(Co), coating had a reduced effect in double-wythe walls as shown in Fig. 8b. For specimens D_C1_(Co) and D_G3_(Co) the maximum load was increased by $47 \%$ and $26 \%$ when compared to D_C1 and D_G3 respectively. The maximum recorded load of D_G7_(Co) was 5\% lower than D_G7.

D_C1_(Co) demonstrated an increase in its maximum load that is comparable to the $51 \%$ increase recorded in the case of S_C1_(Co) versus S_C1. This could potentially mean, that full utilization of textile fibre strength was not achieved in D_C1 (which would increase its corresponding maximum load); although the failure mechanism of D_C1 was textile rupture, partial slippage must have occurred as in the case of S_C1. Thus, further tests are required in the future to examine and highlight this behaviour. In the case of D_G3_(Co) and D_G7_(Co) the maximum load was bounded by the shear capacity of the masonry. Hence, although the coating enhanced the properties of the corresponding TRM layers, full utilization of its tensile capacity was not feasible.

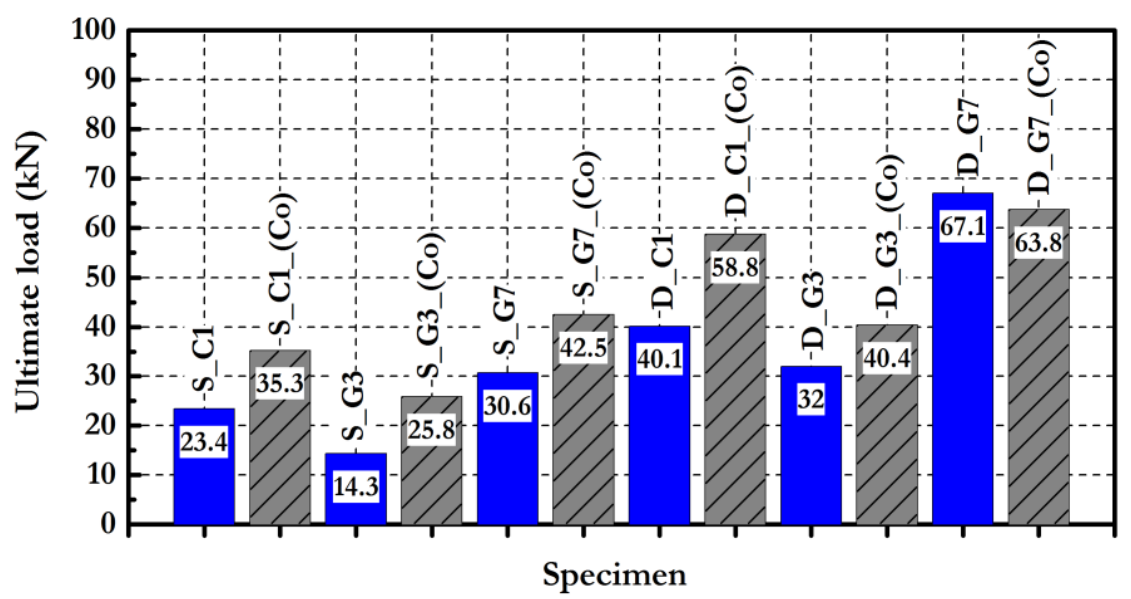

Fig. 9 The effect of coating on the out-of-plane bearing capacity

In terms of deformation capacity, coating enhanced the deformability of all specimens as the enhanced interlocking conditions mitigated textile slippage and allowed for better crack distribution along the length of the wall. Single-wythe walls specimens S_C1_(Co), S_G3_(Co), and S_G7_(Co) demonstrated a 32\%, 142\%, and 275\% increase in their deflection at maximum load when compared to S_C1, S_G3, and S_G7, respectively. Specimens D_C1_(Co), D_G3_(Co), and D_G7_(Co) also demonstrated increased 
1 displacements at maximum load, i.e., $8 \%, 232 \%$, and 5\% when compared to D_C1, D_G3,

2 and D_G7, respectively.

3 The marginal increase observed in the deformability of specimens D_C1_(Co) and D_G7_(Co) when compared to their uncoated counterparts is attributed to different reasons. In the case of 1 layer of carbon fibre textile TRM, coating improved bonding between the textile and the mortar matrix and resulted in a much stiffer configuration than D_C1. Indeed, the post-cracking stiffness of D_C1_(Co) is significantly larger than the corresponding stiffness of D_C1 (see also Fig. 4b); it should be highlighted that such pronounced increase is not observed in all other specimens. This further supports the hypothesis previously made that partial textile slippage occurred in D_C1. When 7 layers of glass fibre textile were used, both D_G7 and D_G7_(Co) failed in shear dominated modes; hence coating did not provide any significant advantage to an already over-reinforced specimen.

\subsection{The effect of number of layers}

Increasing the number of layers resulted in a significant increase in the load bearing-capacity of both single and double-wythe walls as demonstrated in Fig. 10. Single-wythe walls specimens strengthened with 7 layers of TRM, i.e., S_G7, S_G7_(Co) and S_B7 demonstrated an increase in their corresponding maximum loads of $114.0 \%, 65 \%$ and $92 \%$, respectively when compared to the specimens strengthened with three layers of TRM, i.e., S_G3, S_G3_(Co), S_B3. The corresponding load-deflection paths are shown in Fig. 5a. Furthermore, in double-wythe walls specimens, i.e., D_G7, D_G7_(Co), D_B7 the maximum load increased by $110 \%, 58 \%, 54 \%$, respectively, compared to the specimens strengthened with three layers of TRM composite, i.e., D_G3, D_G3_(Co), and D_B3; see also Fig. 5b.

The maximum load was increased proportionally to the additional reinforcement when uncoated glass textile was utilised. Since textile rupture finally occurred in single and doublewythe walls (after shear failure initiation) the maximum tensile strength of the fibre-textile was attained. This was not the case when coated textiles were used where shear/ shear-flexure failure of the wall preceded the flexural strength of the fibre textile and complete utilisation of the fibre textile material did not occur. However, even in those cases where increasing the number of layers did not alter the failure mode, the increase in maximum load has been substantial, as shown in Fig. 8a and b. This highlights the fact that adding reinforcement layers enhances bonding of the textile fibre reinforcement within the matrix thus minimizing roving slippage hence increasing the textile reinforcement effective strength.

In terms of deformability, single-wythe specimens S_G7, S_G7_(Co), and S_B7 demonstrated increased deflection at maximum load, namely $20 \%, 85 \%$, and $26 \%$, compared to S_G3, S_G3_(Co), and S_B3 respectively as shown in Fig. 5a. The increase is more pronounced in the case where the specimen response was governed by a drastic shift from a bending to a shear dominated failure mode which is also consistent with the recorded increase in the corresponding maximum loads.

This response however was not confirmed in the case of stiff double-wythe configurations. The deformability of D_G7 was increased by $97 \%$ compared to D_G3 (Fig. 5b); this again is consistent with the shift in the failure mode. On the contrary, displacement at the maximum load for D_G7_(Co) and D_B7 was decreased by $38 \%$ and $23 \%$, when compared to D_G3_(Co) and D_B3 respectively. These specimens failed in a shear dominated mode hence in terms of deformability, the additional TRM layers led to a stiffer configuration due to the increased axial stiffness of the strengthening layer. This is indeed verified by the initial 
and post-cracking stiffness of specimens that is significantly increases in the case of D_G7_(Co) and D_B3 compared to D_G3_(Co) and D_B3 respectively as shown in Fig. 4b.

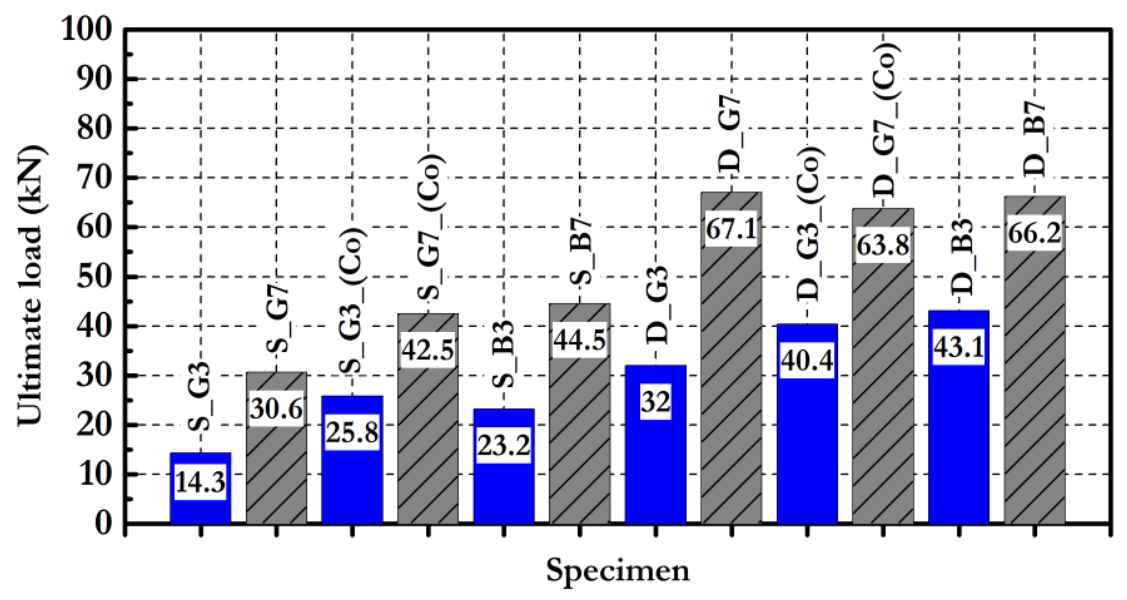

Fig. 10 The effect of number of layers in the out-of-plane bearing capacity

\subsection{The effect of the textile material}

The effect of the textile material in the overall response of the TRM strengthened specimens is shown in Fig. 5e, g and Fig. 5f, h for single- and double-wythe walls, respectively. The maximum loads recorded for each specimen are summarized in Fig. 11 with respect also to the comparisons discussed in this Section.

S_G3_(Co) achieved a $11 \%$ higher maximum load, in comparison to S_B3. Furthermore, S_B7 attained a 5\% larger value of the maximum load as compared to S_G7_(Co). In doublewythe walls, D_B7 and D_B3 reached a $4 \%$ and 7\% higher maximum load, compared to D_G7_(Co) and D_G3_(Co), respectively. The similar response of coated glass and coated basalt specimens with respect to the attained maximum loads, also corroborated by the similar failure modes, highlights the effectiveness of the applied coating procedure for the case of the glass fibre textile.

The maximum load of S_G7 was increased by $31 \%$ compared to S_C1. This increase is consistent with the different failure modes observed, i.e., textile rupture as opposed to textile slippage of the roving filaments through the mortar; this occurs even though the axial stiffness of 1 carbon fibre textile layer is equivalent to the axial stiffness of 7 glass fibre textile layers. Hence, this further highlights the enhanced interlocking mechanisms that the additional number of textile fibre layers benefit from.

A similar trend is observed between S_G7_(Co) and S_C1_(Co) where the former failed at a maximum load 20\% higher than the latter. Although S_G7_(Co) failed in shear (shear diagonal tension), S_C1_(Co) failed due to textile rupture; thus, even though the two specimens involve textile material of comparable axial stiffness, employing additional layers of coated glass gave rise to an over-reinforced specimen. This indicates that the single carbon textile composite layer has a lower tensile fracture capacity compared to the 7 layers of coated glass fibre textile composite highlighting now the enhanced interlocking mechanisms between the textile fibre composites themselves. 
1 Double-wythe wall specimen D_G7 resulted in a 67\% higher load than D_C1. Although the axial stiffness of the G7 and C1 TRM layers is equivalent, such a difference is manifested due to the lack of interlocking when a single uncoated layer of fibre-textile is used. DG_7 failed in a shear-flexure failure mode whereas D_C1 failed due to textile rupture; 7 layers of glass fibre textile again resulted in an over-reinforced specimen as in the case of the singlewythe specimens. The corresponding increase in the maximum load of D_G7_(Co) when compared to D_C1_(Co) was 9\%. These specimens failed in a similar failure mode, i.e., shear - flexure failure followed by brick sliding and partial textile rupture or debonding of TRM respectively. Coating in this case dominated the mechanical response of the textile fibre material.

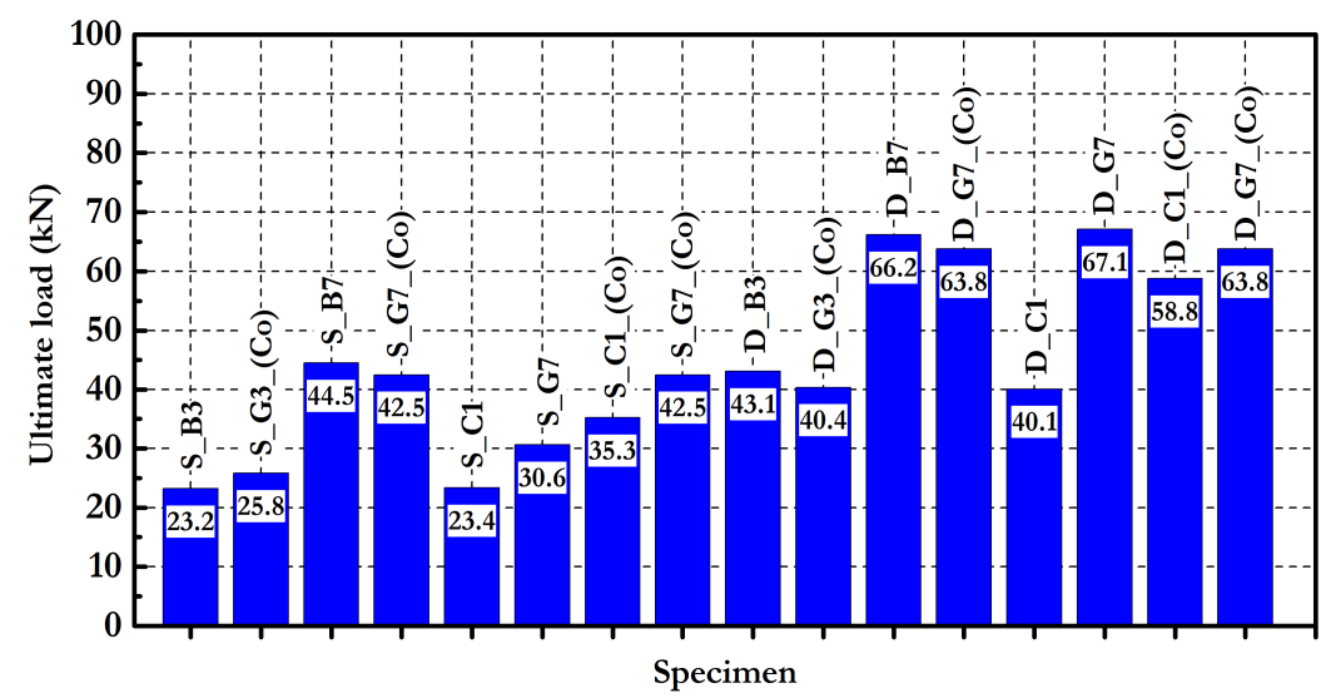

Fig. 11 The effect of textile material in the out-of-plane bearing capacity of single and double-wythe walls

In terms of deformation capacity, single-wythe specimens S_G3_(Co) and S_G7_(Co) resulted in $26 \%$ and $85 \%$ increased displacement at maximum load, compared to $\bar{S} \_B 3$ and S_B7 specimens respectively as shown in Fig. 5a. Double-wythe specimens D_G3_(Co) and D_G7_(Co) lead to $30 \%$ and $4 \%$ increased corresponding displacement of the maximum load, compared to D_B3 and D_B7 specimen, respectively - see also Fig. 5b. With the marginal exception of specimen D_G7_(Co), coated glass fibre textile specimens were significantly more deformable than the corresponding basalt fibre textile specimens although the axial stiffness of the corresponding TRM layers is comparable. This hints to a potential advantage of coated glass fibre textile reinforced mortars that should be further investigated in the future.

\section{Conclusions}

In this work, an experimental campaign was carried out on single and double-wythe masonry walls strengthened with TRM composite material. The objective of this experimental work was to examine and quantify the effect of i) the textile fibres coating; ii) the number of TRM layers and; iii) the type of the textile fibre material utilised, on the out-of-plane flexural response of TRM-strengthened masonry walls. The experimental results obtained are analysed and discussed in terms of maximum load capacity, the deformation capacity and the different failure modes observed due to the aforementioned investigated parameters. Conclusions drawn from the preceding analysis are summarised as follows: 
- The application of epoxy-resin coating resulted in specimens of increased maximum load capacity with respect to their uncoated counterparts, both in single and doublewythe walls. This is attributed to i) the enhanced bonding between the textile fibre and the mortar matrix due to the stiffening of the rovings and their increased surface roughness and ii) increase in the tensile strength of the fibre textile due to improved friction conditions between individual fibres within a roving.

- This was not the case for the D_G7 and D_G7_(Co) specimens where the difference in the recorded maximum loads was marginal. In both specimens, the shear capacity of the masonry wall controlled the corresponding failure modes. Hence, increasing the number of layers has an impact similar to the application of coating by improving interlocking conditions between the fibre textile reinforcement and the matrix.

- Increasing the number of TRM layers by 2.3 times, i.e., from 3 to 7 , resulted in a maximum load increase of 2.1 times for the case of the uncoated glass fibre textile material, both in single and double-wythe walls. However, the maximum load increase achieved in the case of the coated glass fibre textile TRM was 1.6 times in both single and double-wythe walls. In the case of coated basalt fibre textile TRM the corresponding increase of the load capacity was 1.9 and 1.5 times in single and double walls, respectively. Employing 7 layers of coated textile fibre TRM led to overreinforced specimens whose strength was bound by the masonry shear strength.

- Coated Basalt and coated glass fibre textile performed similarly in terms of load bearing capacity, both in single and double-wythe walls. Hence, the custom coating procedure described in this work, which can also be implemented on site, results in a strengthening configuration that is equivalent to that of an industrially manufactured textile composite material.

- The deformability of S_G7_(Co) was significantly increased compared to S_B7 specimen. Although the axial stiffness and strength of the TRM in both cases was practically identical glass textile fibre reinforcement seems to be providing an advantage that should be further investigated in the future.

- In all cases examined bonding achieved between the TRM and the masonry substrate was optimum as debonding only occurred after the maximum load was attained. As manifested by $\mathrm{P}_{\max }$ to $\mathrm{P}_{\text {con }}$ ratio TRM effectiveness was more pronounced in singlewythe walls compared to the much stiffer double-wythe walls. In the latter, the maximum load of the strengthened specimens was bounded by the masonry shear capacity. 
[1]. Lourenço, P.B., Melo, Â., and Carneiro, M.,(2005). Remedial measures for Cathedral of Porto: A post-modern conservation approach.

[2]. Dizhur, D., Ingham, J., Moon, L., Griffith, M., Schultz, A., Senaldi, I., Magenes, G., Dickie, J., Lissel, S., and Centeno, J.,(2011). Performance of masonry buildings and churches in the 22 February 2011 Christchurch earthquake, Bulletin of the New Zealand Society for Earthquake Engineering, 44(4): p. 279-296.

[3]. Verstrynge, E., Schueremans, L., Van Gemert, D., and Wevers, M.,(2009). Monitoring and predicting masonry's creep failure with the acoustic emission technique, NDT \& E International, 42(6): p. 518-523.

[4]. Department of Transport, "Failure of Bridge RDG1 48 (River Crane) between Whitton and Feltham": UK, (2009)

[5]. Hamoush, S.A., Mcginley, M.W., Mlakar, P., Scott, D., and Murray, K.,(2001). Outof-plane strengthening of masonry walls with reinforced composites, Journal of Composites for Construction, 5(3): p. 139-145.

[6]. Galati, N., Tumialan, G., and Nanni, A.,(2006). Strengthening with FRP bars of URM walls subject to out-of-plane loads, Construction and Building Materials, 20(1): p. 101-110.

[7]. EN 1998-1(2005). Eurocode 8: Design of structures for earthquake resistance-Part 1: General rules, seismic actions and rules for buildings, European Committee for Standardization, Brussels.

[8]. Vintzeleou, E. and Tassios, T.,(1989). Seismic behaviour and design of infilled RC frames, International Journal of Earthquake Engineering and Engineering Seismology, 3(2): p. 22-28.

[9]. Tomazevic, M., Earthquake-resistant design of masonry buildings, Vol. 1: World Scientific, (1999).

[10]. Sweidan, R.I., "The application of fiber reinforced plastics to the strengthening of masonry structures", Massachusetts Institute of Technology, (1992)

[11]. Schwegler, G. Masonry construction strengthened with fiber composites in seismically endangered zones. In The 10th European Conference on Earthquake Engineering, Vienna, Austria. 1994.

[12]. Triantafillou, T.C. and Fardis, M.N.,(1997). Strengthening of historic masonry structures with composite materials, Materials and Structures, 30(8): p. 486-496.

[13]. Triantafillou, T.C.,(1998). Strengthening of masonry structures using epoxy-bonded FRP laminates, Journal of composites for construction, 2(2): p. 96-104.

[14]. Valuzzi, M., Tinazzzi, D., and Modena, C. Strengthening of masonry structures under compressive loads by using FRP strips. In 6th Int. Conf. on Fibre-Reinforced Plastics for Reinforced Concrete Structures. 2003. World Scientific.

[15]. Kuzik, M.D., Elwi, A.E., and Cheng, J.R.,(2003). Cyclic flexure tests of masonry walls reinforced with glass fiber reinforced polymer sheets, Journal of Composites for Construction, 7(1): p. 20-30.

[16]. Ehsani, M., Saadatmanesh, H., Abdelghany, I., and Elkafrawy, W.,(1993). Flexural behavior of masonry walls strengthened with composite fabrics, Special Publication, 138: p. 497-508.

[17]. Hamed, E. and Rabinovitch, O.,(2010). Lateral out-of-plane strengthening of masonry walls with composite materials, Journal of Composites for Construction, 14(4): p. 376-387. 
[18]. Foraboschi, P.,(2004). Strengthening of masonry arches with fiber-reinforced polymer strips, Journal of Composites for Construction, 8(3): p. 191-202.

[19]. Bati, S.B. and Rovero, L.,(2008). Towards a methodology for estimating strength and collapse mechanism in masonry arches strengthened with fibre reinforced polymer applied on external surfaces, Materials and Structures, 41(7): p. 1291-1306.

[20]. Fuggini, C., Chatzi, E., and Zangani, D.,(2013). Combining Genetic Algorithms with a Meso-Scale Approach for System Identification of a Smart Polymeric Textile, Computer-Aided Civil and Infrastructure Engineering, 28(3): p. 227-245.

[21]. Tetta, Z.C. and Bournas, D.A.,(2016). TRM vs FRP jacketing in shear strengthening of concrete members subjected to high temperatures, Composites Part B: Engineering, 106: p. 190-205.

[22]. Raoof, S.M., Koutas, L.N., and Bournas, D.A.,(2016). Bond between textilereinforced mortar (TRM) and concrete substrates: Experimental investigation, Composites Part B: Engineering, 98: p. 350-361.

[23]. Papanicolaou, C., Triantafillou, T., and Lekka, M.,(2011). Externally bonded grids as strengthening and seismic retrofitting materials of masonry panels, Construction and Building Materials, 25(2): p. 504-514.

[24]. Faella, C., Martinelli, E., Nigro, E., and Paciello, S. Tuff masonry walls strengthened with a new kind of C-FRP sheet: experimental tests and analysis. In Proceedings of the 13th world conference on earthquake engineering paper, Vancouver, B.C., Canada. 2004.

[25]. Prota, A., Marcari, G., Fabbrocino, G., Manfredi, G., and Aldea, C.,(2006). Experimental in-plane behavior of tuff masonry strengthened with cementitious matrix-grid composites, Journal of Composites for Construction, 10(3): p. 223-233.

[26]. Papanicolaou, C.G., Triantafillou, T.C., Karlos, K., and Papathanasiou, M.,(2007). Textile-reinforced mortar (TRM) versus FRP as strengthening material of URM walls: in-plane cyclic loading, Materials and structures, 40(10): p. 1081-1097.

[27]. Augenti, N., Parisi, F., Prota, A., and Manfredi, G.,(2010). In-plane lateral response of a full-scale masonry subassemblage with and without an inorganic matrix-grid strengthening system, Journal of Composites for Construction, 15(4): p. 578-590.

[28]. Bernat, E., Gil, L., Roca, P., and Escrig, C.,(2013). Experimental and analytical study of TRM strengthened brickwork walls under eccentric compressive loading, Construction and Building Materials, 44: p. 35-47.

[29]. Parisi, F., Iovinella, I., Balsamo, A., Augenti, N., and Prota, A.,(2013). In-plane behaviour of tuff masonry strengthened with inorganic matrix-grid composites, Composites Part B: Engineering, 45(1): p. 1657-1666.

[30]. Cevallos, O., Olivito, R., Codispoti, R., and Ombres, L.,(2015). Flax and polyparaphenylene benzobisoxazole cementitious composites for the strengthening of masonry elements subjected to eccentric loading, Composites Part B: Engineering, 71: p. 82-95.

[31]. Noor-E-Khuda, S., Dhanasekar, M., and Thambiratnam, D.P.,(2016). Out-of-plane deformation and failure of masonry walls with various forms of reinforcement, Composite Structures, 140: p. 262-277.

[32]. Almeida, J.A., Pereira, E.B., and Barros, J.A.,(2015). Assessment of overlay masonry strengthening system under in-plane monotonic and cyclic loading using the diagonal tensile test, Construction and Building Materials, 94: p. 851-865.

[33]. Faella, C., Martinelli, E., Paciello, S., and Perri, F. Composite materials for masonry structures: the adhesion issue. In Proceedings of the 3rd conference on mechanics of 
masonry structures strengthened with composite materials: modeling, testing, design, control-MuRiCo3, Venice, Italy. 2009.

[34]. D'ambrisi, A., Feo, L., and Focacci, F.,(2013). Experimental and analytical investigation on bond between Carbon-FRCM materials and masonry, Composites Part B: Engineering, 46: p. 15-20.

[35]. Garmendia, L., San-José, J., García, D., and Larrinaga, P.,(2011). Rehabilitation of masonry arches with compatible advanced composite material, Construction and Building Materials, 25(12): p. 4374-4385.

[36]. Alecci, V., Focacci, F., Rovero, L., Stipo, G., and De Stefano, M.,(2016). Extrados strengthening of brick masonry arches with PBO-FRCM composites: Experimental and analytical investigations, Composite Structures, 149: p. 184-196.

[37]. Koutas, L., Triantafillou, T., and Bousias, S.,(2014). Analytical modeling of masonryinfilled RC frames retrofitted with textile-reinforced mortar, Journal of Composites for Construction, 19(5): p. 04014082.

[38]. Wang, X., Ghiassi, B., Oliveira, D.V., and Lam, C.,(2017). Modelling the nonlinear behaviour of masonry walls strengthened with textile reinforced mortars, Engineering Structures, 134: p. 11-24.

[39]. Kolsch, H.,(1998). Carbon fiber cement matrix (CFCM) overlay system for masonry strengthening, Journal of Composites for Construction, 2(2): p. 105-109.

[40]. Papanicolaou, C.G., Triantafillou, T.C., Papathanasiou, M., and Karlos, K.,(2008). Textile reinforced mortar (TRM) versus FRP as strengthening material of URM walls: out-of-plane cyclic loading, Materials and Structures, 41(1): p. 143-157.

[41]. Harajli, M., Elkhatib, H., and San-Jose, J.T.,(2010). Static and cyclic out-of-plane response of masonry walls strengthened using textile-mortar system, Journal of materials in civil engineering, 22(11): p. 1171-1180.

[42]. Tetta, Z.C., Koutas, L.N., and Bournas, D.A.,(2015). Textile-reinforced mortar (TRM) versus fiber-reinforced polymers (FRP) in shear strengthening of concrete beams, Composites Part B: Engineering, 77: p. 338-348.

[43]. Babaeidarabad, S., Caso, F.D., and Nanni, A.,(2013). Out-of-plane behavior of URM walls strengthened with fabric-reinforced cementitious matrix composite, Journal of Composites for Construction, 18(4): p. 04013057.

[44]. Valluzzi, M.R., Da Porto, F., Garbin, E., and Panizza, M.,(2014). Out-of-plane behaviour of infill masonry panels strengthened with composite materials, Materials and Structures, 47(12): p. 2131-2145.

[45]. Martins, A., Vasconcelos, G., Fangueiro, R., and Cunha, F.,(2015). Experimental assessment of an innovative strengthening material for brick masonry infills, Composites Part B: Engineering, 80: p. 328-342.

[46]. EN 1015-11(1993). Methods of test for mortar for masonry-Part 11: Determination of flexural and compressive strength of hardened mortar, European Committee for Standardization, Brussels.

[47]. Tetta, Z.C., Koutas, L.N., and Bournas, D.A.,(2016). Shear strengthening of full-scale RC T-beams using textile-reinforced mortar and textile-based anchors, Composites Part B: Engineering, 95: p. 225-239.

[48]. BS EN (1996). Eurocode 6-Design of masonry structures-Part 1-1: General rules for reinforced and unreinforced masonry structures, British Standards Institution, London.

[49]. De Felice, G., De Santis, S., Garmendia, L., Ghiassi, B., Larrinaga, P., Lourenço, P.B., Oliveira, D.V., Paolacci, F., and Papanicolaou, C.G.,(2014). Mortar-based 
systems for externally bonded strengthening of masonry, Materials and Structures, 47(12): p. 2021-2037.

[50]. Garmendia, L., Marcos, I., Garbin, E., Valluzzi, M.R.,(2014). Strengthening of masonry arches with Textile-Reinforced Mortar: experimental behaviour and analytical approaches, Materials and Structures, 47(12): p. 2067-2080.

[51]. Donnini, J., Corinaldesi, V., Nanni, A.,(2016). Mechanical properties of FRCM using carbon fabrics with different coating treatments, Composites Part B: Engineering, 88: p. 220-228.

[52]. MSJC (2002). Building code requirements for masonry structures. ACI530-02/ASCE 5-02/TMS 402-02. USA: Masonry Standards Joint Committee.

[53]. Carloni, C., Bournas, D.A., Carozzi, F.G., D’Antino, T., Fava, G., Focacci, F., Giacomin, G., Mantegazza, G., Pellegrino, C., Perinelli., C., and Poggi, C., Fiber reinforced composites with cementitious (inorganic) matrix. Chapter 9 in: Design procedures for the use of composites in strengthening of reinforced concrete structures - State of the art report of the RILEM TC 234-DUC, (Eds: C. Pellegrino and J. Sena-Cruz); 2015; 349-391, Springer, RILEM STAR Book Series.

[54]. EN 1052-11 (1998). Methods of test for masonry-Part 1: Determination of compressive strength, European Committee for Standardization, Brussels.

[55]. Firmo, J.P., Correia, J.R., Bisby, L.A.,(2015). Fire behaviour of FRP-strengthened reinforced concrete structural elements: A state-of-the-art review, Composites Part B: Engineering, 80: p. 198-216.

[56]. Correia JR. GFRP pultruded profiles in civil engineering: hybrid solutions, bonded connections and fire behavior [PhD thesis in Civil Engineering]. Lisbon, Portugal: Instituto Superior Tecnico-Universidade de Lisboa; 2008.

[57]. BS EN 772-1 (2011) Method of tests for mesonry units-Part 1: Determination of compressive strength, British Standards Institution, London.

[58]. Mosallam, A.S.,(2007). Out-of-plane flexural behavior of unreinforced red brick walls strengthened with FRP composites, Composites Part B: Engineering, 38: p. 559-574.

[59]. Ascione L, De Felice C., De Santis S.,(2015). A qualification method for externally bonded Fibre Reinforced Cementitious Matrix (FRCM) strengthening systems, Composites Part B: Engineering, 78: p.497-506.

[60]. Lignola, G.P., Caggegi, C., Ceroni, F., De Santis, S., Krajewski P., Lourenço, P.B, Morganti, M., Papanicolaou, C., Pellegrino, C., Prota, A., Zuccarino, L.,(2017). Performance assessment of basalt FRCM for retrofit applications on masonry, Composites Part B: Engineering, 128: p.1-18.

[61]. Carozzi, F.G, and Poggi, C.,(2015). Mechanical properties and debonding strength of fabric reinforced Cementitious Matrix (FRCM) systems for masonry strengthening, Composites Part B: Engineering, 70: p.215-230. [62]. Raoof S., and Bournas, D.A.,(2017). TRM versus FRP in flexural strengthening of RC Beams: Behaviour at figh temperatures, Construction and Building Materials, 154, 424-437.

[63]. Raoof, S., and Bournas, D.A.,(2017). Bond between TRM versus FRP composites and concrete at high temperatures", Composites Part B: Engineering, 127, 150-165. 